\title{
Fairness, Search Frictions, and Offshoring ${ }^{1}$
}

\author{
Devashish Mitra \\ Priya Ranjan \\ Syracuse University \\ University of California - Irvine \\ dmitra@maxwell.syr.edu \\ pranjan@uci.edu
}

Current version: March, 2012

\begin{abstract}
Fairness considerations within the firm are introduced into the determination of wages in a two factor Pissarides-style model of search unemployment to study its implications for the unemployment rates of unskilled and skilled workers in both the closed economy case and when the economy can offshore some inputs. While the effect of a fair-wage constraint on unskilled workers takes the form of an increase in their wage and unemployment, we also find interesting effects on skilled workers in a closed economy. The skilled wage and skilled unemployment move in directions opposite to each other, with the actual direction of their movement depending on the elasticity of substitution between skilled and unskilled labor. The impact of offshoring of the services of unskilled labor on the unemployment of unskilled workers is stronger in the presence of fairness considerations than in the case when search frictions are the only source of unemployment. Finally, offshoring insulates the skilled labor market outcomes from fairness concerns that are present in a closed economy.
\end{abstract}

Key words: Fair wages, unemployment, overhiring effect, offshoring

JEL Classification Codes: F16, F40, E24, J64

\footnotetext{
${ }^{1}$ We would like to thank seminar participants at UC-Riverside, University of Melbourne and University of New South Wales and conference participants at the Dallas Fed-SMU Conference on Globalization, Political Economy and Trade Policy held at Southern Methodist University for useful comments and suggestions. We are also indebted to Carl Davidson and John Leahy for very helpful comments on an earlier version. The standard disclaimer applies.
} 


\section{Introduction}

Over the last three decades, there has emerged a vast and well-developed literature on the theory of search unemployment. ${ }^{1}$ Empirical support for the existence of substantial search frictions and their importance in generating unemployment has made the introduction of such frictions into economic models of labor markets the most standard and accepted way of modeling unemployment. Given the broad interest in studying the labor market implications of globalization, economists have been using search theoretic models to study the impact of globalization on unemployment ${ }^{2}$. The question of wage determination in search models of unemployment is far from settled, however. The standard approach, including that in the literature on trade and search unemployment, is to use Nash bargaining between the worker and the employer. Mortensen and Pissarides (1999) discuss the robustness of the key insights of the search unemployment models with regard to alternative wage determination procedures. However, they do not discuss how fairness considerations in wage determination can affect unemployment. In this paper we introduce fairness considerations within the firm into the determination of wages in a two factor Pissarides-style model of search unemployment to study its implications for the unemployment rates of unskilled and skilled workers in both the closed economy case and when the economy can offshore some inputs.

The motivation for introducing fairness considerations comes from extensive surveys of managers and workers, sociological studies of work environments, firm-level studies of pay structures, experiments, personnel management textbooks etc, which provide a wealth of evidence supporting the assumption or idea of a fair-wage. ${ }^{3}$ In a recent book, Akerlof and Shiller (2009) argue that fairness is an important aspect of "the thought patterns that animate people's ideas and feelings,"

\footnotetext{
${ }^{1}$ See Pissarides (2000) for an excellent and comprehensive treatment of search unemployment.

${ }^{2}$ See Davidson and Matusz (2004) for an in-depth treatment of search unemployment and some other forms of unemployment in an open-economy setting (including their own pioneering work in this area over two decades). Recent work on search unemployment in an open-economy setting also incoporates firm heterogeneity under monopolistic competition. See for instance important work by Helpman and Itskhoki (2010), Felbermayr, Larch and Lechthaler (2008) and Felbermayr, Prat and Schmerer (2011). An important paper that further brings in worker heterogeneity into the framework of search unemployment with firm heterogeneity under monopolistic competition is Helpman, Itskhoki and Redding (2010).

${ }^{3}$ See for instance Akerlof and Yellen (1990), Bewley (2005) and Howitt (2002) for a survey of the evidence.
} 
whose study is crucial in understanding how economies behave. Akerlof and Yellen (1990) actually focus on such fairness or fair-wage considerations to explain the existence of unemployment. As noted by Grossman and Helpman (2008), fairness considerations may spur firms to offshore a part of their production process making it imperative to study the implications of fairness considerations in the open economy.

Our baseline model is a standard Pissarides-style search model with two factors, skilled and unskilled labor. In that framework, due to search frictions there is positive unemployment of both types of labor. To that framework, we incorporate fairness, which is internal to the two types of workers within a firm, as an additional consideration in wage determination. For wages to be "fair" within a firm, the inequality between the wages of skilled and unskilled workers employed by that firm has to be equal to or below a certain maximum acceptable level. This constraint on the internal wage inequality within a firm is factored into the firm-worker wage negotiations (bargaining). Therefore, unlike Akerlof and Yellen (1990) fairness considerations are not the sole source of unemployment and unlike the standard Pissarides model search frictions are not the sole source unemployment in our set up.

As wages are determined through Nash bargaining with workers in the second stage conditional on the employment choice in the first stage, there is a possibility of the overhiring effect first identified by Stole and Zwiebel (1996). The overhiring effect refers to a firm's incentive to overhire workers in the first stage to keep the wages lower in the second stage. However, the overhiring effect that is present when a firm employs a single type of worker gets complicated when there are different types of workers. For example, when both skilled and unskilled workers are hired by a firm, hiring an extra skilled worker lowers the marginal product of skilled workers, and thereby lowers their wage. However, it also raises the marginal product of unskilled workers, and consequently their wage increases. In this setting, whether a net 'overhiring effect' is present for a particular type of worker depends on the relative bargaining power of that worker type and the elasticity of substitution between different types of workers as shown in a very nice paper by Cahuc, Marque and Wasmer (2008).

To focus on the new issues resulting from the fair-wage considerations, we neutralize the overhiring effect for each type of worker by assuming equal bargaining power of the two types of workers. That is, any saving in the skilled wage bill resulting from hiring an extra skilled worker is completely 
offset by the increase in the unskilled wage bill. However, the introduction of a fair-wage constraint restores the overhiring effect for skilled workers for the following reason. Hiring an additional skilled worker lowers the wage of skilled workers by reducing their marginal product as before. But it does not raise the wage of unskilled workers anymore. In fact within our set up, that emphasizes the within-firm nature of the fair-wage constraint, employing an additional skilled worker also reduces the fair wage paid to unskilled workers. Therefore, in this set up not only is the overhiring effect restored through the introduction of our firm-specific (internal to the firm) fair-wage constraint, it is stronger than what would be obtained when there is an economywide or industrywide fair wage taken parametrically by each firm.

Looking at the impact of the fair-wage constraint on unemployment, we find that unemployment of unskilled workers increases unambiguously but the impact on the unemployment of skilled workers is ambiguous. Since unskilled workers become more expensive due to fair-wage considerations, it is easy to understand why their unemployment would increase. The discussion of the overhiring effect for skilled workers above would suggest that unemployment of skilled workers should decrease. However, the overhiring effect discussed above was a partial-equilibrium effect relevant for a firm in isolation. For the economy as a whole, there is a general equilibrium effect counteracting the partial-equilibrium overhiring effect. This comes from the fact that, at the aggregate level, the lower relative employment of unskilled workers reduces the marginal product of skilled workers rendering the net effect on skilled unemployment ambiguous. Intuitively, we can expect the extent to which the marginal product of skilled labor increases with unskilled employment to depend on the degree of complementarity versus substitutablity between skilled and unskilled labor in the production function. Indeed, numerical simulations suggest that when the elasticity of substitution between the two types of labor is high, the unemployment of skilled workers is lower with a binding fair wage constraint than in the absence of it. Also, starting from such a fair-wage constrained equilibrium, an increase in the fairness parameter increases the relative employment of skilled workers unambiguously but has ambiguous effects on other labor market outcomes. In this case, the motive to over-hire skilled workers due to the fair wage constraint is present both before and after the increase in the fairness parameter. An increase in the fairness parameter makes the overhiring effect stronger, and this effect may or may not be offset by the general-equilibrium effect (working in the opposite direction) discussed earlier. 
There is another interesting result, driven by the overhiring effect brought about by fair wage considerations, in the paper. For intermediate relative factor endowments (skill abundance), introducing fairness considerations along with search frictions can lead to the possibility of multiple equilibria: countries with identical preference for fairness and relative factor endowments can have different wages and unemployment rates.

Next, we use our model to study the implications of fair wage considerations for the unemployment of skilled and unskilled workers when the economy can offshore the production of certain inputs. This makes our paper the first to study the impact of offshoring on unemployment of different types of workers. To avoid discussing too many cases, we study the case of offshoring of unskilled jobs when the fair wage constraint is binding. In this case we obtain an equilibrium where some firms offshore production of the input produced by unskilled labor while others hire domestic unskilled labor to produce these inputs. It is shown that a decrease in the cost of offshoring increases the extent of offshoring, reduces skilled unemployment, increases both skilled and unskilled wage and increases unskilled unemployment. Since skilled and unskilled unemployment move in opposite directions, the impact on aggregate unemployment is ambiguous. To clearly see the role of the fair wage constraint in determining the impact of offshoring, the results are contrasted with the case when the fair wage constraint does not bind. In the latter case the adjustment in the unskilled labor market in response to offshoring takes place through a decrease in wage and an increase in unemployment. Since the fairness considerations tie the unskilled wage to the skilled wage, the unskilled wage moves in the opposite direction (opposite to the unconstrained case with only search frictions) when the constraint binds and hence offshoring has a larger impact on the unemployment of unskilled workers.

More interestingly, we find that opening up the economy to offshoring eliminates the ambiguity in the effects of the fair-wage constraint on various labor-market outcomes that was obtained in the closed economy case. In particular, an increase in the society's preference for fairness results in an increase in unskilled wage and unskilled unemployment, without affecting skilled wage and unemployment. In other words, the effect on skilled labor that was present in the closed economy case is taken over in the offshoring case by an adjustment in the size of offshoring itself in response to a change in the fairness parameter. Since there exist offshoring firms which use only skilled labor and an imported input, the reward to skilled workers is pinned down by the cost of the imported 
input (in conjunction with the zero profit condition). Any increase in the concern for fairness does not affect the offshoring firms and hence leaves the skilled labor market unaffected. In the unskilled labor market, however, we get an increase in wage (due to the increase in the fairness parameter) and consequently an increase in unemployment which keeps the overall cost of hiring unskilled labor unchanged for firms that do not offshore. ${ }^{4}$

We believe that the theoretical exercises we perform in this paper are important for several reasons. The main reason is that attitudes towards fairness differ across societies which could potentially account for differences in unemployment rates even if the search frictions are of similar magnitude. As well, countries with similar degrees of search frictions but different degress of concern for fairness could respond differently to shocks such as globalization or skill biased technological change. Based on survey evidence of attitudes to poverty and income, one can argue that social norms of fairness are stronger in Europe than in the US. This is illustrated by calculations by Alesina and Glaeser (2005), based on data from the World Values Survey for the years 1983-97. While only 29 percent of the responders from the US believe that the poor are trapped in poverty, about 60 percent of the European responders believe this to be the case. Furthermore, only 30 percent in the US believe that luck determines income, while 54 percent in the EU believe in luck being a determinant. Alesina and Glaeser also find that 60 percent of the Americans surveyed believe that the poor are lazy, while only 26 percent of the EU nationals surveyed believe so. ${ }^{5}$ Finally, using the International Social Survey Program (ISSP) surveys of public opinion, Osberg and Smeeding (2006) find in the case of the US "less concern for leveling up at the bottom of the distribution than in other nations." That is, there is less concern for raising the income of the poor relative to the mean income in the US than in other countries.

As mentioned above, our paper is the first to study the impact of offshoring on unemployment

\footnotetext{
${ }^{4}$ Note that with the small country assumption we have in this paper the insulation is perfect and complete. If the country is large so that it can affect the world price of the imported input, there is still insulation but it is partial.

${ }^{5}$ Alesina and Angeletos (2005) point to the fact that while the pre-tax inequality is much higher in the US than in Europe (Gini coefficient of 38.5 as opposed to 29.1), the redistributive policies are much more extensive and the tax structure much more progressive in the latter. They argue that "the difference in political support for redistribution appears, rather, to reflect a difference in social perceptions regarding the fairness of market outcomes and the underlying sources of income inequality."
} 
of different types of workers. This is another reason why we believe our work is useful. The fair-wage set up, we believe, makes it even more useful as we can bring in an often-neglected reason for offshoring in the literature. When a firm employs different kinds of workers, fairness concerns across the various types of workers can introduce a distortion into the production process. Offshoring might be a way of getting rid of this form of distortion. In such a context, it might be important to look at the impact of offshoring on the wage and unemployment rates of both skilled and unskilled workers. ${ }^{6}$ The result here that we find interesting and, we believe, can have some policy relevance is that offshoring insulates the skilled labor market outcomes from fairness concerns. As well, the impact of offshoring on the unemployment of unskilled workers is stronger in the presence of fairness considerations.

Among related papers, Kreickemeier and Nelson (2006) extend the Akerlof and Yellen (1990) model to a two-sector setting to study the impact of international trade and technology shocks on unemployment and relative wages. ${ }^{7}$ The unemployment in their model arises solely from the fair-wage consideration and no search frictions are modeled. Another difference between the Kreickemeier-Nelson paper and ours is that while in their paper the fair wage, determined in general equilibrium, is taken as given (parametric) by every firm, in our paper the fair wage is determined within the firm and the fair-wage constraint is factored into the firm-employee wage negotiations.

Another advance in this literature is a very recent innovative working paper by Davidson, Matusz and Nelson (2012) that tries to model fairness of a different kind within a search unemployment model in an open economy setting. They introduce both a "scarring effect" or a loss in utility from one's own unemployment and another loss in utility from the unemployment of others, representing the fairness considerations in their model. In this context, they also look at the political economy of trade policy. Their focus is not on fairness in wage determination and nor is there room for any "overhiring effects" in their setting.

\footnotetext{
${ }^{6} \mathrm{~A}$ recent paper that looks at fairness considerations in wages (in both closed and open economy settings), but not within a seach framework, is Grossman and Helpman (2008). In that paper, the utility derived by a worker is increasing in her own wage but decreasing in the average wage of the firm. Because of this approach to modeling fair wages, there is no unemployment of any kind.

${ }^{7}$ See also Egger and Kreickemeier (2009), where fairness is defined differently in terms of the relationship between wages and profits.
} 
While Cahuc, Marque and Wasmer were the first to study in great detail the overhiring effect arising from the monopsony power of firms in the labor market in a search model with many different types of labor, our paper is, to our knowledge, the first to show the presence of a stronger overhiring effect due to the presence of the fairness constraint. This additional source of the overhiring effect is then eliminated in firms that resort to the offshoring of the services of unskilled workers.

In the next section, we will present our basic theoretical framework which consists only of search frictions and no fairness considerations. In that section, we also present the autarky equilibrium within such a framework. We then introduce the fair-wage constraint within this framework and then analyze its impact for the closed-economy case (along with some comparative statics) in section 3. In section 4, we open the economy up to offshoring, where we look at the new quilibrium and then perform detailed comparative statics with respect to the offshoring cost and the fairness parameter. We then discuss possible extensions of the offshoring case in section 5 and finally conclude in section 6.

\section{The basic theoretical framework}

\subsection{The goods market}

Let there be three types of agents in the economy: $S$ skilled workers, $L$ unskilled workers, and a large number of entrepreneurs. Entrepreneurs have access to the technology to produce a final good, $Z$, using skilled and unskilled labor. The production function for the final good $Z$, which is constant returns to scale (CRS), is given by

$$
Z=F(s, l)
$$

where $s$ and $l$, respectively, are the numbers of skilled and unskilled workers employed. We also assume that the final good, $Z$, is the numeraire. 


\subsection{The labor market}

Our description of the labor market is a static version of Pissarides (2000) along the lines of Helpman and Itskhoki (2010). ${ }^{8}$

Entrepreneurs must post vacancies to hire skilled and unskilled workers to undertake production. Once a vacancy is matched with a worker, she is hired to work for that firm (entrepreneur).

The labor markets for both skilled and unskilled are characterized by a CRS matching technology that depends on the number of searchers (size of the labor force) and the number of job vacancies. ${ }^{9}$

Let $u_{i}$ denote the unemployment rate of factor $i, \theta_{i}$ the vacancy rate (i.e., the number of vacancies divided by the labor force), $S$ the economy's endowment of skilled labor, and $L$ the endowment of unskilled labor. Since the model is static where all workers search for a job, and a fraction $1-u_{i}$ of workers of type- $i$ is matched (with vacancies), $\theta_{i}$ is also the measure of market tightness. Then, we write the number of matches for each factor as constant-returns-to-scale functions as follows:

$$
M\left(\theta_{s} S, S\right)=M\left(\theta_{s}, 1\right) S ; \quad M\left(\theta_{l} L, L\right)=M\left(\theta_{l}, 1\right) L
$$

where subscript $s$ denotes skilled labor and subscript $l$ denotes unskilled labor.

Define $m_{s} \equiv \frac{M\left(\theta_{s} S, S\right)}{S}=M\left(\theta_{s}, 1\right)$ and $m_{l} \equiv \frac{M\left(\theta_{l} L, L\right)}{L}=M\left(\theta_{l}, 1\right)$ as the matching rates for the two factors, where $m_{i}^{\prime}\left(\theta_{i}\right)>0$. Define $q\left(\theta_{i}\right) \equiv \frac{m_{i}}{\theta_{i}}$. CRS in matching implies $q^{\prime}\left(\theta_{i}\right)<0$. With this notation, the probability of finding a job for a searcher of type- $i$ is $\theta_{i} q\left(\theta_{i}\right)$, and the probability of filling up a vacant job of type- $i$ is $q\left(\theta_{i}\right)$. The former is an increasing function of market tightness, and the latter is a decreasing function of market tightness. The number of vacancies that a firm needs to create for it to expect to create one job at the end of the matching process is $\frac{1}{q\left(\theta_{i}\right)}$. For a large firm, by the law of large numbers the actual ratio of vacancies to jobs (matches) created will be $\frac{1}{q\left(\theta_{i}\right)}$.

\footnotetext{
${ }^{8}$ In a recent technical note, Helpman and Itskhoki (2009) develop a dynamic model along similar lines to show that its steady state looks similar to their static model. We have also wroked through a dynamic version of our model and are able to confirm that the steady state results from such a model are no different from the results we obtain from the static model presented in this paper. The detailed analytics of the dynamic version are available from the authors upon request.

${ }^{9}$ Pissarides (2000) describes the empirical support for a CRS matching function.
} 
We will restrict attention to the case where skilled workers would never prefer to search for an unskilled job, even if that were possible. ${ }^{10}$ The unemployment rate for each factor is given by:

$$
u_{i}=1-m_{i}=1-\theta_{i} q\left(\theta_{i}\right)
$$

An entrepreneur posting vacancies must pay a recruitment cost of $c_{i}(i=s, l)$ units of the final good per vacancy posted. Since a firm needs to post on average $\frac{1}{q\left(\theta_{i}\right)}$ vacancies to create one job, the vacancy cost per worker employed equals $\frac{c_{i}}{q\left(\theta_{i}\right)}$. Once a job is filled, the entrepreneur receives the value of the marginal product of that factor less the factoral wage, $w_{i}$, where the wage is denoted in units of the final good.

\subsection{The entrepreneur's problem and wage determination in the absence of a fair-wage constraint}

We solve the entrepreneur's problem in two stages. In the first stage, employment and the number of vacancies are chosen, anticipating the wages as functions of skilled and unskilled employment (determined through bargaining in the second stage) correctly. Then given the employment levels chosen in the first stage, the wage rate is determined in the second stage by a process of bargaining between the entrepreneur and the worker, along the lines of Stole and Zwiebel (1996). A worker and her employer bargain with each other taking into account the impact of the worker's possible exit on wages of other employees. In other words, we allow the possibility of renegotiation of the employer with other employees if bargaining fails with any employee, and this feature is completely factored into the bargaining process. ${ }^{11}$

\subsubsection{First-stage employment determination}

The discussion above implies that our overall equilibrium concept is one of subgame perfect equilibrium which is solved using backward induction. That is, taking as given the employment chosen in the first stage, in the second stage the wages are determined through a process of simultaneous

\footnotetext{
${ }^{10}$ This can be done by imposing reasonable restrictions on the parameters of production and matching functions and on the relative factor endowments of skilled and unskilled labor.

${ }^{11}$ A special case of this, where the worker and employer have equal bargaining weights, exactly boils down to the Shapley value solution to a cooperative, multilateral bargaining problem.
} 
Stole-Zwiebel bargaining between the firm and the workers. Anticipating the second stage wage as a function of employment, the firm optimally chooses employment in the first stage. The entrepreneur solves the following problem in the first stage taking into account the impact of employment choice on the wages paid in the second stage.

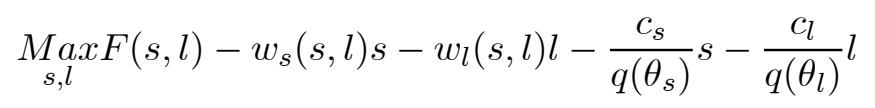

The first-order conditions for the optimal choices of $s$ and $l$ are given by

$$
\begin{aligned}
& F_{1}(s, l)-w_{s}-s \frac{\partial w_{s}}{\partial s}-l \frac{\partial w_{l}}{\partial s}=\frac{c_{s}}{q\left(\theta_{s}\right)} \\
& F_{2}(s, l)-w_{l}-s \frac{\partial w_{s}}{\partial l}-l \frac{\partial w_{l}}{\partial l}=\frac{c_{l}}{q\left(\theta_{l}\right)}
\end{aligned}
$$

where subscripts "1" and "2" denote partial derivatives of the production function with respect to the first and second arguments, respectively.

\subsubsection{Second-stage wage determination}

Denote the expressions on the l.h.s in the two equations (5) and (6) by $J_{i}, i=s, l$, where $J_{i}$ is the surplus of the firm from hiring the marginal worker of type- $i$. Assuming unemployment benefit to be zero, the bargaining weight of a worker of type- $i$ to be $\beta_{i}$, the bargained wage for a worker of type- $i$ is obtained as follows.

$$
w_{i}^{b}=\underset{w_{i}}{\arg \max } w_{i}^{\beta_{i}} J_{i}^{1-\beta_{i}}
$$

Using (5), (6), the first-order conditions of the above maximization problem yields the following expressions for wages for the two types of workers.

$$
\begin{aligned}
& w_{s}=\beta_{s}\left[F_{1}(s, l)-s \frac{\partial w_{s}}{\partial s}-l \frac{\partial w_{l}}{\partial s}\right] \\
& w_{l}=\beta_{l}\left[F_{2}(s, l)-s \frac{\partial w_{s}}{\partial l}-l \frac{\partial w_{l}}{\partial l}\right]
\end{aligned}
$$

The above is a system of differential equations, where each worker's bargained wage is a fraction of the surplus she creates in the form of her marginal product plus the reduction in the wage bill (or minus the increase in the wage bill) of the existing workers through her employment (relative to the situation where she exits and wages with other workers are renegotiated). As seen from the above differential equations, there are own as well as cross effects of skilled and unskilled employment on wages. The solution to the above system of differential equations is given by 


$$
\begin{aligned}
& w_{s}=\int_{0}^{1} z^{\frac{1-\beta_{s}}{\beta_{s}}} F_{1}\left(s z, l z^{\left(\frac{\beta_{l}}{1-\beta_{l}}\right)\left(\frac{1-\beta_{s}}{\beta_{s}}\right)}\right) d z \\
& w_{l}=\int_{0}^{1} z^{\frac{1-\beta_{l}}{\beta_{l}}} F_{2}\left(s z^{\left(\frac{\beta_{s}}{1-\beta_{s}}\right)\left(\frac{1-\beta_{l}}{\beta_{l}}\right)}, l z\right) d z
\end{aligned}
$$

Denote $s / l$ by $t$. Given that $F(s, l)$ is CRS, we can write $F(s, l)=l F(t ; 1)$. Denote $F(t ; 1)$ by $f(t)$ and it follows that $F_{1}(s, l)=f^{\prime}(t)$ and $F_{2}(s, l)=f(t)-t f^{\prime}(t)$. Next, we derive the following useful result.

Lemma 1: When $\beta_{s}=\beta_{l}=\beta, w_{s}(t)=\beta f^{\prime}(t) ; w_{l}(t)=\beta\left(f(t)-t f^{\prime}(t)\right)$

Proof: Follows from (10) and (11).

That is, under the assumption of identical bargaining power of the two types of workers, the wages are simply a fraction $\beta$ of the respective marginal products of labor. This is despite the fact that while choosing employment in stage 1 the firm takes into account its effect on the wage in the second stage captured by terms $i \frac{\partial w_{i}}{\partial j}$, for $i, j=s, l$ in the first-order conditions (5) and (6). For example, $s \frac{\partial w_{s}}{\partial s}$ captures the effect of hiring an additional skilled worker on skilled wage. If hiring an additional skilled worker lowers their marginal product it will reduce the Nash bargained wage that firms have to pay to skilled workers. Therefore, the value of a skilled job to the firm would exceed the marginal product of skilled labor due to this effect giving rise to the Stole-Zwiebel overhiring effect. However, an additional skilled worker also increases the marginal product of unskilled workers which would lead to an increase in the unskilled wage $\left(\frac{\partial w_{l}}{\partial s}>0\right)$, leading to a reduced value of a skilled job for the firm. For a constant returns to scale production function with the same bargaining weights for a skilled and an unskilled worker relative to the employer, these two effects cancel out in the determination of the wage bill. Thus, the surplus that is shared between the worker and the firm is the worker's marginal product and it is shared according to their bargaining weights.

When $\beta_{s} \neq \beta_{u}$, the two effects described above do not cancel out. For a Cobb-Douglas production of the form: $F(s, l)=s^{\alpha} l^{1-\alpha}$, the following can be verified easily from (10) and (11).

$$
w_{s}(t)=\frac{\beta_{s}\left(1-\beta_{l}\right) \alpha t^{\alpha-1}}{\left(1-\beta_{l}\right)+(1-\alpha)\left(\beta_{l}-\beta_{s}\right)} ; w_{l}(t)=\frac{\beta_{l}\left(1-\beta_{s}\right)(1-\alpha) t^{\alpha}}{\left(1-\beta_{s}\right)+\alpha\left(\beta_{l}-\beta_{s}\right)} .
$$


It follows that

$$
\begin{aligned}
& w_{s}(t)>\beta_{s} f^{\prime}(t) \text { and } w_{l}(t)<\beta_{l}\left(f(t)-t f^{\prime}(t)\right) \text { if } \beta_{s}>\beta_{l} \\
& w_{s}(t)<\beta_{s} f^{\prime}(t) \text { and } w_{l}(t)>\beta_{l}\left(f(t)-t f^{\prime}(t)\right) \text { if } \beta_{s}<\beta_{l}
\end{aligned}
$$

Intuitively, if $\beta_{s}>\beta_{l}$, then the net effect is positive for skilled workers because hiring an extra skilled worker saves more in skilled wages than the extra unskilled wage that firms have to pay. Therefore, this leads to overhiring of skilled workers. If $\beta_{s}<\beta_{l}$, then we get the opposite result. This is similar to the results obtained in Cahuc et al. (2008) in a much more general setting. Since our focus is on a comparison of unconstrained and fair-wage constrained equilibria, there is no loss of generality in restricting to the case $\beta_{s}=\beta_{l}=\beta$ because, as shown later, the incentive to overhire skilled workers is more or to underhire is less in the constrained case than in the unconstrained case, irrespective of the bargaining power.

\subsection{Closed-economy equilibrium in the absence of a fair-wage constraint}

Since firms take $\theta_{s}$ and $\theta_{l}$ as given, we can solve for equilibrium values of $\theta_{s}$ and $\theta_{l}$ by obtaining expressions for the demands and supplies of the two factors of production as functions of $\theta_{s}$ and $\theta_{l}$. We prove the following useful lemma next.

$$
\text { Lemma 2: } w_{s}(t)=\frac{\beta}{1-\beta} \frac{c_{s}}{q\left(\theta_{s}\right)} ; w_{l}(t)=\frac{\beta}{1-\beta} \frac{c_{l}}{q\left(\theta_{l}\right)}
$$

Proof: Follows from (5) and (8), and (6) and (9), respectively.

Intuitively, Nash bargaining implies that the wage, $w_{i}$ equals $\frac{\beta}{1-\beta} J_{i}$, where $J_{i}$ is the surplus of the firm from hiring the marginal worker of type- $i$. The first order condition for the hiring of a worker of type- $i$ implies that the surplus, $J_{i}$, must equal the per-worker recruiting $\operatorname{cost} \frac{c_{i}}{q\left(\theta_{i}\right)}$.

To derive relative labor demand and supply functions in terms of relative market tightness which allows us to solve the model diagrammatically, we assume that the matching function is of Cobb-Douglas form given as follows.

Assumption 1: $m\left(\theta_{i}\right)=\mu \theta_{i}{ }^{\delta}$ and hence $q\left(\theta_{i}\right)=\mu \theta_{i}{ }^{\delta-1}$.

Under the above assumption, the relative demand for skilled labor as a function of $\frac{\theta_{s}}{\theta_{l}}$ can be obtained from lemmas 1 and 2. Lemma 2 implies that

$$
\frac{w_{s}(t)}{w_{l}(t)}=\frac{c_{s} q\left(\theta_{l}\right)}{c_{l} q\left(\theta_{s}\right)}=\frac{c_{s}}{c_{l}}\left(\frac{\theta_{s}}{\theta_{l}}\right)^{1-\delta}
$$


Next, use lemma 1 to re-write the wages in (13) and obtain

$$
\frac{f^{\prime}\left(t^{d}\right)}{f\left(t^{d}\right)-t^{d} f^{\prime}\left(t^{d}\right)}=\frac{c_{s}}{c_{l}}\left(\frac{\theta_{s}}{\theta_{l}}\right)^{1-\delta}
$$

where $t^{d}$ denotes the relative demand for skilled labor as a function of $\frac{\theta_{s}}{\theta_{l}}$. Since $f^{\prime \prime}(t)<0$, the relative demand $t^{d}$ is decreasing in $\frac{\theta_{s}}{\theta_{l}}$. This is shown using a downward sloping curve denoted by $R L D^{u}$ in Figure 1 in $\left(\frac{s}{l}, \frac{\theta_{s}}{\theta_{l}}\right)$ space. This is intuitive as the relative cost of employing skilled labor (relative to unskilled) is increasing in its relative market tightness. The superscript $u$ stands for the relatively "undistorted" case (later referred to as the "unconstrained case").

Having obtained an expression for relative demand, next we derive an expression for the relative supply of two types of labor. Denoting the economy's endowments of skilled and unskilled labor by $S$ and $L$ respectively, the relative supply (available for employment) is given by $\frac{S\left(1-u_{s}\right)}{L\left(1-u_{l}\right)}$, which using (3) and assumption 1 becomes

$$
t^{s}=\frac{S \theta_{s} q\left(\theta_{s}\right)}{L \theta_{l} q\left(\theta_{l}\right)}=\frac{S}{L}\left(\frac{\theta_{s}}{\theta_{l}}\right)^{\delta}
$$

The above is clearly increasing in $\frac{\theta_{s}}{\theta_{l}}$. In other words, because the relative employment rate is increasing in the relative market tightness of skilled labor, the relative supply of skilled labor available for employment is also increasing in its relative market tightness. This is shown using upward sloping lines denoted by $R L S$ in Figure 1.

The intersection of the downward sloping relative demand with the upward sloping relative supply determines the autarky equilibrium in the unconstrained case as shown in Figure 1. Having obtained the equilibrium $t$ from the intersection of $R L D^{u}$ and $R L S$ in Figure 1, the corresponding equilibrium values of $w_{s}, w_{l}, \theta_{s}$, and $\theta_{l}$ can be obtained from the expressions in lemmas 1 and 2 . Denote the unconstrained equilibrium wage and market tightness variables by $w_{l}^{u}, w_{s}^{u}, \theta_{l}^{u}, \theta_{s}^{u}$.

\section{Introduction of a fair-wage constraint}

There can be many reasons for why firms want to pay at least a fair wage to workers. As discussed by Akerlof and Yellen (1990), workers exert less than full effort if they are not paid a fair wage (a behavior, which workers themselves may view or justify as pay back for the unfair wage being paid). Paying at least a fair-wage ensures that workers work at their maximum efficiency, which 
can do away with the extra cost incurred in recruiting additional workers. ${ }^{12}$ Alternatively, paying a fair wage may be part of corporate social responsibility or a norm in society. The concept of fair wage also may be related to the issue of inequality aversion. That is, workers detest wage inequality beyond a certain level. In this case, the unskilled wage cannot be less than a fraction of the skilled wage. The modeling of fair wage below is closest to the inequality aversion story. That is, we assume that the unskilled wage cannot be below a certain fraction $\tau$ of the skilled wage. ${ }^{13}$

The next issue that we have to deal with in modeling fair wage is to decide whether it operates at the firm level or the industry level. If fair-wage considerations operate at the industry level, then the firm can take the fair wage (determined in general equilibrium) as parametrically given. In the text below we provide the description of the analytically more difficult case of fair wage determined at the firm level, which may be more appropriate given our favored interpretation of fair wage arising from the inequality aversion of workers ${ }^{14}$. The case of the fair wage determined at the industry level is given in the appendix.

\subsection{The entrepreneur's problem and wage determination under a fair-wage con- straint}

Now, the entrepreneur's problem effectively becomes:

$$
\underset{s, l}{\operatorname{Max}}\left\{F(s, l)-w_{s}(s, l) s-\operatorname{Max}\left\{w_{l}(s, l), \tau w_{s}(s, l)\right\} l-\frac{c_{s}}{q\left(\theta_{s}\right)} s-\frac{c_{l}}{q\left(\theta_{l}\right)} l\right\}
$$

As a result, the first order conditions for the optimal choices of $s$ and $l$ in the case where the constraint is expected to bind are given by

$$
\begin{aligned}
f^{\prime}(t)-w_{s}-s \frac{\partial w_{s}}{\partial s}-l \tau \frac{\partial w_{s}}{\partial s} & =\frac{c_{s}}{q\left(\theta_{s}\right)} \\
f(t)-t f^{\prime}(t)-s \frac{\partial w_{s}}{\partial l}-l \tau \frac{\partial w_{s}}{\partial l}-\tau w_{s} & =\frac{c_{l}}{q\left(\theta_{l}\right)}
\end{aligned}
$$

\footnotetext{
${ }^{12}$ The need for paying at least a fair wage may be more pressing in scenarios such as ours, where there is a recruitment cost per worker in addition to the wage paid. In such cases, paying less than fair wage will result in waste of resources in recruitment of extra workers for the firm to hire any given number of total efficiency units.

${ }^{13}$ In an extension we allow the concern for fairness to depend on the unemployment level of unskilled workers. That is, a higher unemployment reduces the concern for fairness or inequality.

${ }^{14}$ This is similar to the approach of Grossman and Helpman (2008), although, they do not use a search theoretic framework.
} 
If the fairwage was determined at the industry level then the term $l \tau \frac{\partial w_{s}}{\partial i}(i=s, l)$ would equal zero. However, when the fairwage is determined at the firm level, the term $l \tau \frac{\partial w_{s}}{\partial i}$ captures the fact that any change in skilled wage affects the fair wage as well, which is taken into account by the firm.

From the inspection of (17) and (18) note that $w_{s}$ is going to be a function of both $t$ and $\tau$. Writing $w_{s}$ as a function of $t$ and $\tau$, the first order conditions above can be re-written as

$$
\begin{aligned}
f^{\prime}(t)-w_{s}(t, \tau)-(t+\tau) \frac{\partial w_{s}(t, \tau)}{\partial t} & =\frac{c_{s}}{q\left(\theta_{s}\right)} \\
f(t)-t f^{\prime}(t)+\left(t^{2}+\tau t\right) \frac{\partial w_{s}(t, \tau)}{\partial t}-\tau w_{s}(t, \tau) & =\frac{c_{l}}{q\left(\theta_{l}\right)}
\end{aligned}
$$

Using Nash bargaining as before, the wage of the skilled workers is given by the following differential equation

$$
w_{s}(t, \tau)=\beta\left[f^{\prime}(t)-(t+\tau) \frac{\partial w_{s}(t, \tau)}{\partial t}\right]
$$

Compare above with the expression for skilled wage given in lemma 1 for the unconstrained case and note the extra term $(t+\tau) \frac{\partial w_{s}(t, \tau)}{\partial t}$. If $\frac{\partial w_{s}(t, \tau)}{\partial t}<0$, then $(21)$ implies that hiring an extra skilled worker yields two additional benefits compared to the first best case. First, the term $t \frac{\partial w_{s}(t, \tau)}{\partial t}$ captures the gain that arises from the saving of wage bill on skilled workers which is not offset by a rise in the wage bill of unskilled workers. In the unconstrained case, the saving on wage bill of skilled was offset by the increased wage of the unskilled. Second, there are savings on the unskilled because the fairwage for the unskilled $\tau w_{s}(t, \tau)$ goes down as well. Therefore, the overhiring effect is likely to be much stronger if the constraint binds.

It can be verified that the solution to the differential equation in (21), under the restriction that $\lim _{t \rightarrow 0} t w_{s}(t, \tau)=0$, is given by

$$
w_{s}(t, \tau)=(t+\tau)^{-\frac{1}{\beta}} \int_{0}^{t}(x+\tau)^{\frac{1-\beta}{\beta}} f^{\prime}(x) d x
$$

It is worth pointing out that we cannot establish the direction of the slope of $w_{s}$ with respect to $t$ in (22). When $\frac{\partial w_{s}(t, \tau)}{\partial t}>0$, we run into an existence problem, and therefore, we restrict our model to the case when $\frac{\partial w_{s}(t, \tau)}{\partial t}<0$ holds. ${ }^{15}$ We make this requirement explicit in the assumption below.

\footnotetext{
${ }^{15}$ As shown in the appendix, when fair wage is determined at the industry level, the skilled wage depends only on $t$ and not on $\tau$. Moreover, $w_{s}^{\prime}(t)<0$ always obtains.
} 
Assumption 2: $\frac{\partial w_{s}(t, \tau)}{\partial t}<0$

The model can be solved as follows. For a given $\frac{\theta_{s}}{\theta_{l}}$ ratio, the expression for relative demand for skilled labor, $t^{d}$, can be obtained from (19) and (20) as follows.

$$
\Psi\left(t^{d}, \tau\right) \equiv \frac{f^{\prime}\left(t^{d}\right)-w_{s}\left(t^{d}, \tau\right)-\left(t^{d}+\tau\right) \frac{\partial w_{s}\left(t^{d}, \tau\right)}{\partial t^{d}}}{f\left(t^{d}\right)-t^{d} f^{\prime}\left(t^{d}\right)+\left(\left(t^{d}\right)^{2}+\tau t^{d}\right) \frac{\partial w_{s}\left(t^{d}, \tau\right)}{\partial t^{d}}-\tau w_{s}\left(t^{d}, \tau\right)}=\frac{c_{s}}{c_{l}}\left(\frac{\theta_{s}}{\theta_{l}}\right)^{1-\delta}
$$

Under assumption 2 the following lemma is proved in the appendix.

Lemma 3: The relative demand for skilled labor, $t^{d}$, given in (23) is decreasing in $\frac{\theta_{s}}{\theta_{l}}$

\subsection{Closed-economy equilibrium in the presence of a fair-wage contraint}

The relative demand for skilled labor given in (23) along with the relative supply equation given in (15) determines the equilibrium $t$ and $\frac{\theta_{s}}{\theta_{l}}$.when the fair wage constraint binds. Then $w_{s}$ is determined from (22), and $\theta_{s}$ and $\theta_{l}$ are determined from (19) and (20).

Next, we note from (19) and (21) the following useful equilibrium relationship between the skilled wage and the market tightness for skilled workers.

$$
\text { Lemma } 4: w_{s}(t, \tau)=\frac{\beta}{1-\beta} \frac{c_{s}}{q\left(\theta_{s}\right)}
$$

The reason that the expression for the skilled wage as function of $\theta_{s}$ is unchanged from the expression in lemma 2 for the unconstrained case is that the wage of skilled workers is still determined by Nash bargaining.

\subsection{Comparing constrained and unconstrained relative demands}

Since the relative supply of skilled labor is given by (15) in both the unconstrained and constrained cases, in order to compare the constrained and unconstrained equilibria we need to compare the constrained relative demand with the unconstrained relative demand for skilled labor. Recall from lemma 2 that for any $\frac{\theta_{s}}{\theta_{l}}$ the unconstrained $\frac{w_{l}}{w_{s}}$ is given by $\frac{c_{l}}{c_{s}}\left(\frac{\theta_{s}}{\theta_{l}}\right)^{\delta-1}$. It is worth clarifying that this $\frac{w_{l}}{w_{s}}$ ratio is not the unconstrained equilibrium wage ratio, but simply the wage ratio that would result for any $\frac{\theta_{s}}{\theta_{l}}$ ratio which is taken as given by the firms. Recall that firms are not wage takers, but they do take the levels of market tightness as given. Therefore, the fair wage constraint binds 
if $\tau>\frac{w_{l}}{w_{s}}=\frac{c_{l}}{c_{s}}\left(\frac{\theta_{s}}{\theta_{l}}\right)^{\delta-1}$ or if

$$
\left(\frac{\theta_{s}}{\theta_{l}}\right)>\left(\frac{c_{l}}{\tau c_{s}}\right)^{\frac{1}{1-\delta}}
$$

The above inequality implies that for any $\tau$ there exists a $\theta(\tau) \equiv\left(\frac{c_{l}}{\tau c_{s}}\right)^{\frac{1}{1-\delta}}$ such that for $\frac{\theta_{s}}{\theta_{l}}>\theta(\tau)$ the constraint binds while for $\frac{\theta_{s}}{\theta_{l}}<\theta(\tau)$ it is non-binding. Therefore, for $\frac{\theta_{s}}{\theta_{l}}<\theta(\tau)$ the constrained relative demand for skilled labor coincides with the unconstrained relative demand. Next, we prove the following lemma in the appendix.

Lemma 5: The constrained relative demand for skilled labor given in (23) is strictly greater than the unconstrained relative demand given in (14) for $\frac{\theta_{s}}{\theta_{l}} \geq \theta(\tau)$.

Thus, the relative demand curve with the possibility of the fair-wage constraint becomes the one denoted by $R L D^{c}$ in Figure 1 which has two segments, one for values of $\frac{\theta_{s}}{\theta_{l}}$ greater than $\theta(\tau)$, and the other for values less than $\theta(\tau)$ which corresponds to the unconstrained relative demand curve.

It is easy to understand why the constrained relative demand curve lies to the right of the unconstrained one. Since unskilled labor becomes more expensive, firms substitute skilled labor for unskilled labor and hence the relative demand for skilled labor increases. But, why is there a jump at $\frac{\theta_{s}}{\theta_{l}}=\theta(\tau)$ ? This has to do with the additional overhiring effect arising from the fairness constraint. Now, hiring an additional skilled worker not only reduces the wage of skilled workers at the bargaining stage, but also reduces the wage of the unskilled workers because the latter is tied to the skilled wage through the fairness constraint. Therefore, firms have an incentive to hire more skilled workers as soon as the constraint becomes binding.

\subsection{Comparing constrained and unconstrained equilibria in a closed economy}

Let us compare the autarky equilibrium in the absence of fairness considerations given by point $e_{1}$ in Figure 1 with an autarky equilibrium constrained by the fair-wage condition. To make the comparison of constrained and unconstrained equilibria precise, we do the comparison when the constraint is just binding, that is $\tau=\frac{c_{l}}{c_{s}}\left(\frac{\theta_{s}^{u}}{\theta_{l}^{u}}\right)^{\delta-1}$. The new equilibrium where the constraint binds is obtained by the intersection of $R L D^{c}$ with $R L S$ and is at point $e_{2}$ in Figure 1. That is,

$$
\frac{\theta_{s}^{c}}{\theta_{l}^{c}}>\frac{\theta_{s}^{u}}{\theta_{l}^{u}} ; t^{c}>t^{u}
$$


where we use the superscript $c$ to denote the value of a variable in a constrained equilibrium. Next, we prove the following lemma in the appendix.

Lemma 6: $\theta_{l}^{c}<\theta_{l}^{u}$

Intuitively, since $\frac{\theta_{s}^{c}}{\theta_{l}^{c}}>\frac{\theta_{s}^{u}}{\theta_{l}^{u}}, \theta_{l}^{c} \geq \theta_{l}^{u}$ would imply $\theta_{s}^{c}>\theta_{s}^{u}$. Since the price of the final good is 1 by the choice of the numeraire, $\theta_{l}^{c}>\theta_{l}^{u}$ and $\theta_{s}^{c}>\theta_{s}^{u}$ will violate the zero profit condition in a constrained equilibrium by making it costlier to hire both types of labor. Therefore, $\theta_{l}^{c}<\theta_{l}^{u}$, but the impact on $\theta_{s}$ is ambiguous. From lemmas 2 and 4 we infer that the change in the skilled wage is in the same direction as the change in $\theta_{s}$.

Numerical simulations show that the impact on $\theta_{s}$ depends on the elasticity of substitution between skilled and unskilled labor denoted by $\sigma$. There is a cut off value of elasticity of substitution $\sigma^{*}$ such that for $\sigma<\sigma^{*}, \theta_{s}$ decreases while for $\sigma>\sigma^{*}, \theta_{s}$ increases. Below is a numerical example.

Numerical Example: $c_{l}=c_{s}=1, L=2, S=1, \beta=\delta=.5, \mu=1.25 ; F(s, l)=\frac{\left(\gamma s^{\rho}+(1-\gamma) l^{\rho}\right)^{\frac{1}{\rho}}}{\left(\gamma^{\sigma}+(1-\gamma)^{\sigma}\right)^{\frac{1}{\sigma-1}}}$ is the CES production function with $\sigma=\frac{1}{1-\rho}$ being the elasticity of substitution between $s$ and $l$. When $\gamma=.5$, the cutoff value of $\sigma$ turns out to be 0.8 . That is, as long as $\sigma \leq 0.8$, constrained skilled unemployment is higher than the unconstrained skilled unemployment. For $\sigma>0.8$, the constrained skilled unemployment is lower than the unconstrained skilled unemployment. Constrained unskilled unemployment is always higher than the unconstrained unskilled unemployment.

Since the unemployment rate $u_{i}$ is inversely related to $\theta_{i}$, the result on the comparison between unconstrained and constrained equilibria can be summarized as follows.

Proposition 1: In an equilibrium where the fair-wage constraint is just binding, unskilled unemployment is higher and skilled unemployment (and skilled wage) is lower (higher) than in an unconstrained equilibrium for high (low) values of elasticity of substitution between skilled and unskilled labor.

We can understand the results in intuitive terms as follows. When the fair wage constraint starts binding, the firms substitute skilled workers for unskilled workers because the latter have become more expensive. This firm level response has the following general equilibrium effect. Since 
the usage of unskilled workers goes down, the marginal product of skilled workers goes down in aggregate because of the constant returns to scale production function. A decrease in the marginal product of skilled labor is associated with lower market tightness and greater unemployment for these workers. The magnitude of the reduction in market tightness for skilled workers depends on $\sigma$. A higher $\sigma$ implies a smaller decrease in the marginal product of skilled workers and hence a smaller reduction in the market tightness of skilled workers. Therefore, the higher the $\sigma$ the smaller the increase in the unemployment of skilled workers in the absence of any overhiring effect.

The overhiring effect for skilled workers works via reducing the marginal product of skilled workers when an extra skilled worker is hired. Therefore, the greater the reduction in the marginal product of skilled workers from hiring an additional skilled worker, the stronger the overhiring effect. Again, the higher the $\sigma$ the greater the decrease in the marginal product of skilled workers and hence the greater the overhiring effect. Therefore, there is greater overhiring of skilled workers when the elasticity of substitution is high.

Based on the discussion above, we expect that when the elasticity of substitution is high, it is more likely that a binding fair-wage constraint will reduce skilled unemployment. This is exactly what we find numerically.

\subsubsection{The possibility of multiple equilibria}

Given the shape of the relative demand curve with fair-wage constraint, it is possible to get multiple equilibria. To see this, suppose the relative supply curve is one denoted by $R L S^{\prime}$ in Figure 1 . Now, if the society did not have any concern for fairness, then the equilibrium would be at $e_{3}$. However, fairness concerns cause a stepward shift in the relative demand curve at $\theta(\tau)$ making $e_{4}$ a candidate for equilibrium as well. That is, both $e_{3}$ and $e_{4}$ are possible equilibria when fairness considerations are present.

The intuition for "multiple equilibria" here is the following. Since the relative cost of labor (wage plus recruitment cost) is positively related to the relative market tightness, the fair-wage

constraint binds if $\frac{\theta_{s}}{\theta_{l}}$ is high. If firms expect $\frac{\theta_{s}}{\theta_{l}}$ to be high and therefore the fair-wage constraint to bind, they will end up hiring more skilled workers relative to unskilled workers due to the overhiring effect discussed earlier. This, in turn, will make the relative market tightness for skilled workers higher creating a "self-fulfilling prophecy." Similarly, if $\frac{\theta_{s}}{\theta_{l}}$ is expected to be low, the fair-wage 
constraint is then not expected to bind, the relative demand for skilled labor is lower, which in turn leads to a low $\frac{\theta_{s}}{\theta_{l}}$ and thus, an effectively unconstrained outcome.

As seen from Figure 1, we have multiple possible expectations regarding $\frac{\theta_{s}}{\theta_{l}}$, when relative supply is in the intermediate range, which happens only when the relative endowment of skilled labor is in the intermediate range. In other words, if the relative endowment of skilled labor is very high (low), which the firms know, they will expect the relative market tightness of skilled labor to be always low (high).

\subsubsection{Comparative statics with respect to the fairness parameter, $\tau$ in a closed econ- omy}

To find out what happens to the relative demand for skilled labor when $\tau$ changes we need to find out what happens to $\Psi\left(t^{d}, \tau\right)$ given in (23) when $\tau$ changes. In order to do that, we need to know in which direction $w_{s}(t, \tau)$ moves in response to a change in $\tau$. Since the partial derivative, $\frac{\partial w_{s}(t, \tau)}{\partial \tau}$ cannot be unambiguously signed we make the following assumption.

Assumption 3: $\frac{\partial w_{s}(t, \tau)}{\partial \tau} \geq 0$

Assumption 3, which states that the skilled wage function is non-decreasing in $\tau$, is a sufficient condition for the following lemma, which is proved in the appendix.

Lemma $7: \frac{\partial \Psi\left(t^{d}, \tau\right)}{\partial \tau}>0$

Intuitively, Nash bargaining (see equation (21)) implies that the net surplus from hiring a skilled worker (1.h.s of (19)) is proportional to the skilled wage. Therefore, if an increase in $\tau$ is associated with an increase in the skilled wage, it implies an increase in the net surplus from skilled labor and hence the relative demand for skilled labor increases.

Now, let us assume that the economy is at a constrained equilibrium, i.e., the relative supply curve in Figure 1 intersects the fair-wage relative demand curve in its upper right-hand downward sloping part (that lies above the cut-off value of $\frac{\theta_{s}}{\theta_{l}}$ at which the fairness constraint binds). An increase in $\tau$ implies from lemma 7 that the relative demand curve shifts to the right in the $\left(\frac{s}{l}, \frac{\theta_{s}}{\theta_{l}}\right)$ space. This implies an increase in the equilibrium $t$ and $\frac{\theta_{s}}{\theta_{l}}$. Since $w_{s}$ is a function of both $t$ and $\tau$, the impact of an increase in $\tau$ on the equilibrium skilled wage can be seen from the following 
expression which is also useful later in discussing the impact of offshoring.

$$
\frac{d w_{s}(t, \tau)}{d \tau}=\frac{\partial w_{s}(t, \tau)}{\partial t} \frac{d t}{d \tau}+\frac{\partial w_{s}(t, \tau)}{\partial \tau}
$$

Since $\frac{\partial w_{s}(t, \tau)}{\partial \tau} \geq 0, \frac{\partial w_{s}(t, \tau)}{\partial t}<0$ and $\frac{d t}{d \tau}>0$, the sign of $\frac{d w_{s}(t, \tau)}{d \tau}$ is ambiguous. In words, since $w_{s}$ is decreasing in $t$ and increasing in $\tau$, an increase in $\tau$ which increases the equilibrium $t$ has an ambiguous effect on the wage of skilled labor. This also implies an ambiguous effect on skilled unemployment from lemma 4 as well as an ambiguous effect on unskilled wage because the latter is simply $\tau w_{s}$. The impact on the unskilled unemployment is theoretically ambiguous as well. To see this, note that the l.h.s of (20) is increasing $t$ (shown in the appendix while proving lemma 3 ). Next, verify that l.h.s of (20) is decreasing in $\tau$. Therefore, the total effect of an increase in $\tau$ on the l.h.s. of (20) is ambiguous and hence the impact on unskilled unemployment is ambiguous.

Proposition 2: Starting from a constrained equilibrium, an increase in the fairness parameter $\tau$ increases the relative usage of skilled labor in the economy but has an ambiguous effect on other labor market outcomes. In particular, it is possible for the skilled wage to increase which from lemma 4 implies that skilled unemployment must decrease.

Before concluding our analysis of the closed economy it is worth pointing out that the results are unambiguous when the fair wage is determined at the industry level in that starting from a constrained equilibrium, an increase in the fairness parameter $\tau$ leads to increases in both skilled and unskilled unemployment. The skilled wage falls and the unskilled wage rises. This is shown in the appendix. The ambiguity in the case of the firm fair wage arises due to the additional overhiring effect. As mentioned earlier, now hiring an additional skilled worker lowers the fair wage as well.

\section{Impact of Offshoring}

For offshoring to be possible, firms have to be able to fragment their production in such a way that semi-finished output, whose production only requires the application of unskilled labor, can be produced in another country (South) and then imported back to be combined with skilled labor at home to produce the final product. To keep things simple, we assume that one unit of this semifinished good or input is a perfect substitute for a unit of domestic unskilled labor. We assume the 
price of this imported input inclusive of the search and trade costs to be fixed, which is equivalent to a small country assumption. ${ }^{16}$ Later we provide an extension where the price of this offshored input is increasing in the amount of offshoring.

Suppose the unit cost (faced at home) of the offshored input is $p_{m}$. Let the amount of this input imported be denoted by $m$. We assume that the quantity of the offshored input is chosen in the first stage along with skilled labor.

Rather than discussing too many cases we discuss the case of offshoring when the fairness constraint binds. Note that fairness considerations can be a motive for firms to offshore to increase their profits.

\subsection{An offshoring firm's problem and its wage determination}

A firm that decides to offshore and not hire unskilled workers domestically, solves the following problem:

$$
\underset{s, m}{\operatorname{Max}} F(s, m)-w_{s}(s, m) s-p_{m} m-\frac{c_{s}}{q\left(\theta_{s}\right)} s
$$

The first order conditions for the above maximization are given by

$$
\begin{aligned}
f^{\prime}\left(t^{o}\right)-w_{s}^{o}\left(t^{o}\right)-t^{o} w_{s}^{o \prime}\left(t^{o}\right) & =\frac{c_{s}}{q\left(\theta_{s}\right)} \\
f\left(t^{o}\right)-t^{o} f^{\prime}\left(t^{o}\right)+\left(t^{o}\right)^{2} w_{s}^{o \prime}\left(t^{o}\right)-p_{m} & =0
\end{aligned}
$$

In the above expressions, the superscript $o$ denotes offshoring firms and $t^{o}$ equals $s^{o} / m$. Following the same procedure as in autarky, the wage of skilled workers in the second stage is given by the following differential equation

$$
w_{s}^{o}\left(t^{o}\right)=\beta\left[f^{\prime}\left(t^{o}\right)-t^{o} w_{s}^{\prime}\left(t^{o}\right)\right]
$$

The solution to the above differential equation is given by

$$
w_{s}^{o}\left(t^{o}\right)=t^{o-\frac{1}{\beta}} \int_{0}^{t^{o}} x^{\frac{1-\beta}{\beta}} f^{\prime}(x) d x
$$

\footnotetext{
${ }^{16}$ This assumption is reasonable if we believe that the South has large quantities of unskilled labor and that fixed labor productivity in a large subsistence, numeraire sector there fixes their unskilled wage.
} 
For a non-offshoring firm, the first order conditions are the same as in autarky given in (19) and (20) which we recall are

$$
\begin{aligned}
f^{\prime}\left(t^{n o}\right)-w_{s}^{n o}\left(t^{n o}, \tau\right)-\left(t^{n o}+\tau\right) \frac{\partial w_{s}^{n o}\left(t^{n o}, \tau\right)}{\partial t^{n o}} & =\frac{c_{s}}{q\left(\theta_{s}\right)} \\
f\left(t^{n o}\right)-t^{n o} f^{\prime}\left(t^{n o}\right)+\left(t^{n o 2}+\tau t^{n o}\right) \frac{\partial w_{s}^{n o}\left(t^{n o}, \tau\right)}{\partial t^{n o}}-\tau w_{s}^{n o}\left(t^{n o}, \tau\right) & =\frac{c_{l}}{q\left(\theta_{l}\right)}
\end{aligned}
$$

where the superscript no denotes non-offshoring firms and $t^{\text {no }}$ equals $s^{\text {no }} / l$. Using Nash bargaining, as in autarky, the wage of a skilled worker is given by the following differential equation

$$
w_{s}^{n o}\left(t^{n o}, \tau\right)=\beta\left[f^{\prime}\left(t^{n o}\right)-\left(t^{n o}+\tau\right) \frac{\partial w_{s}^{n o}\left(t^{n o}, \tau\right)}{\partial t^{n o}}\right]
$$

The solution to the above differential equation is given by

$$
w_{s}^{n o}\left(t^{n o}, \tau\right)=\left(t^{n o}+\tau\right)^{-\frac{1}{\beta}} \int_{0}^{t^{n o}}(x+\tau)^{\frac{1-\beta}{\beta}} f^{\prime}(x) d x
$$

\subsection{Equilibrium under offshoring}

The equilibrium conditions in the two labor markets- demand for each type of labor equals its supply- can be written as follows.

$$
\begin{aligned}
s^{o}+s^{n o} & =S\left(1-u_{s}\right)=S k \theta_{s}^{\delta} \\
l & =L\left(1-u_{l}\right)=L k \theta_{l}^{\delta}
\end{aligned}
$$

where $s^{o}$ is the skilled labor hired by offshoring firms and $s^{n o}$ is the skilled labor hired by nonoffshoring firms.

Under the assumption that an interior equilibrium exists with both offshoring and non offshoring firms (which will be the case if the cost of offshored input is not too low compared to the autarky cost of hiring domestic unskilled labor $)^{17}$, the 6 equations- (26), (27), (29), (30), (31), (33)- determine the key endogenous variables: $t^{n o}, t^{o}, w_{s}^{o}, w_{s}^{n o}, \theta_{s}, \theta_{l}$. Then, the equations (34) and (35) determine

\footnotetext{
${ }^{17}$ The interesting and realistic case is that of a mixed equilibrium in which both offshoring and fully domestic firms exist side by side. The case where all firms in the economy offshore is not interesting since in that case there will be an unskilled unemployment rate of 100 percent, a highly unrealistic situation. As long as $\tau$ is not extremely high and $p_{m}$ is not too low, we will have a mixed equilibrium since the recruitment cost per worker goes to zero as market tightness goes to zero (unemployment goes to 100 percent).
} 
the amounts of skilled and unskilled labor employed, $s^{o}+s^{n o}$ and $l$, and finally, $s^{o}, s^{n o}$, and $m$ are obtained from the definitions of $t^{n o}$ and $t^{o}$.

Even though $t^{o} \neq t^{n o}$, the following lemma is easily verified.

$$
\text { Lemma 8: } w_{s}^{n o}\left(t^{n o}, \tau\right)=w_{s}^{o}\left(t^{o}\right)=\frac{\beta}{1-\beta} \frac{c_{s}}{q\left(\theta_{s}\right)}
$$

The above lemma simply follows from (26) and (28), and (30) and (32), respectively. As mentioned earlier in the contexts of lemmas 2 and 4 , lemma 8 results from the fact that the surplus from hiring an extra skilled worker must equal the recruitment cost. Since the recruitment cost for skilled workers is the same for offshoring and non-offshoring firms, they end up paying identical wage to the skilled workers.

It can also be easily verified from lemma 8 and assumption 3 earlier that $t^{n o} \geq t^{o}$. That is, non-offshoring firms are likely to be more skill intensive than offshoring firms which again arises due to the overhiring effect for non-offshoring firms.

\subsection{Impact of a decrease in the offshoring cost, $p_{m}$}

The following lemma on the impact of a decrease in the cost of offshoring on the endogenous variables of interest is proved in the appendix.

Lemma 9: $\frac{d t^{o}}{d p_{m}}>0, \frac{d t^{n o}}{d p_{m}}>0, \frac{d \theta_{s}}{d p_{m}}<0, \frac{d \theta_{l}}{d p_{m}}>0, \frac{d m}{d p_{m}}<0$.

Intuitively, a decrease in the cost of offshoring induces offshoring firms to substitute the offshored input for domestic skilled labor, thereby lowering their skill intensity. The general equilibrium effect of increased offshoring is a rise in the skilled wage and a decrease in skilled unemployment because at the aggregate level the two types of inputs are complementary. Since the skilled workers have become more expensive, non-offshoring firms economize on skilled workers as well.

An increase in the skilled wage implies an increase in the unskilled wage as well because the fairness constraint is binding. This gives us the following result.

Proposition 3: A decrease in the cost of offshoring increases the extent of offshoring, reduces skilled unemployment, increases both skilled and unskilled wage and increases unskilled unemployment. 
The result above implies that a decrease in the cost of offshoring has an ambiguous impact on aggregate unemployment because the unemployment of unskilled labor increases but the unemployment of skilled labor decreases.

To clearly see the role of the fair-wage constraint in determining the impact of offshoring, we show in the appendix that if the fairness constraint does not bind then a decrease in the cost of offshoring reduces unskilled wage and increases unskilled unemployment. Since the fairness considerations tie the unskilled wage to the skilled wage, the unskilled wage moves in the opposite direction when the constraint binds (relative to the unconstrained case) and hence offshoring has a larger impact on the unemployment of unskilled workers.

\subsection{Impact of an increase in the fairness parameter, $\tau$ in the presence of off- shoring}

In the discussion below we assume that the interior equilibrium with both offshoring and nonoffshoring firms continues to obtain. Since (27) continues to hold and $w_{s}^{o}\left(t^{o}\right)$ is independent of $\tau, t^{o}$ is unchanged despite an increase in $\tau$, which implies from (26) that $\theta_{s}$ is unchanged. It follows from lemma 8 that the skilled wage is unchanged as well. Why is it the case that the skilled labor market remains unaffected by an increase in the concern for fairness in the open economy? Since fairness considerations do not apply to offshoring firms, an increase in the fairness parameter does not affect them directly. The surplus that an offshoring firm gets from a marginal skilled worker remains unchanged, which in turn requires the recruitment cost for skilled workers to remain unchanged for an equilibrium to obtain with both types of firms.

An unchanged $\theta_{s}$ implies from lemma 8 that $w_{s}^{n o}\left(t^{n o}, \tau\right)$ is unchanged as well. That is, $\frac{d w_{s}^{n o}\left(t^{n o}, \tau\right)}{d \tau}=$ 0. Recall from (25) that

$$
\frac{d w_{s}^{n o}\left(t^{n o}, \tau\right)}{d \tau}=\frac{\partial w_{s}^{n o}\left(t^{n o}, \tau\right)}{\partial \tau}+\frac{\partial w_{s}^{n o}\left(t^{n o}, \tau\right)}{\partial t^{n o}} \frac{d t^{n o}}{d \tau}=0
$$

Therefore,

$$
\frac{d t^{n o}}{d \tau}=-\frac{\frac{\partial w_{s}^{n o}\left(t^{n o}, \tau\right)}{\partial \tau}}{\frac{\partial w_{s}^{n o}\left(t^{n o}, \tau\right)}{\partial t^{n o}}}
$$

Recall from assumption 2 that $\frac{\partial w_{s}^{n o}\left(t^{n o}, \tau\right)}{\partial t^{n o}}<0$ and from assumption 3 that $\frac{\partial w_{s}^{n o}\left(t^{n o}, \tau\right)}{\partial \tau} \geq 0$, therefore, $\frac{d t^{n o}}{d \tau} \geq 0$. That is, when $\frac{\partial w_{s}^{n o}\left(t^{n o}, \tau\right)}{\partial \tau}=0, t^{n o}$ is unchanged, but in the case of $\frac{\partial w_{s}^{n o}\left(t^{n o}, \tau\right)}{\partial \tau}>0, \frac{d t^{n o}}{d \tau}>0$. Now an increase in $\tau$ increases $w_{s}^{n o}$ which then is offset by an increase in $t^{n o}$. 
Next, we prove the following lemma on the impact on $\theta_{l}$.

Lemma 10: An increase in $\tau$ leads to a decrease in $\theta_{l}$ in an offshoring equilibrium.

Next, note from the definitions of $t^{n o}$ and $t^{o}$ that $\frac{m}{l}=\frac{t^{n o}}{t^{o}} \frac{s^{o}}{s^{n o}}$. One can view $\frac{m}{l}$ as the extent of offshoring. Imposing factor market equilibrium conditions (34) and (35), we have $\frac{m}{l}=\frac{1}{t^{o}}\left[\frac{S \theta_{s}^{\delta}}{L \theta_{l}^{\delta}}-t^{n o}\right]$. When $t^{n o}$ is unchanged, a decrease in $\theta_{l}$ (in the face of an unchanged $\theta_{s}$ ), brought about by an increase in $\tau$, implies $\frac{m}{l}$ increases. This would be the case when $\frac{\partial w_{s}^{n o}\left(t^{n o}, \tau\right)}{\partial \tau}=0$. However, when $\frac{\partial w_{s}^{n o}\left(t^{n o}, \tau\right)}{\partial \tau}>0, t^{n o}$ increases, in which case the effect of $\tau$ on $\frac{m}{l}$ is theoretically ambiguous. A sufficient condition for an increase in $\tau$ to increase offshoring is $\frac{d s^{n o}}{d \tau} \leq 0$, that is, the share of non-offshoring firms in the hiring of skilled workers does not increase with $\tau$. Since the fairness constraint binds only for non-offshoring firms, an increase in $\tau$ which makes the constraint worse is expected to reduce the share of non-offshoring firms in the economy and hence the sufficient condition is not restrictive. ${ }^{18}$ We thus present the following result.

\section{Proposition 4: Starting from an offshoring equilibrium where the fairness constraint} is binding, an increase in $\tau$ leads to an increase in offshoring, an increase in unskilled wage, and an increase in unskilled unemployment, while the unemployment rate and wage of skilled workers remain unchanged.

By comparing the results in propositions 2 and 4 one can compare the impact of an increase in $\tau$ in the closed economy with that in the open economy. The key difference is in the responses of skilled wage and unemployment to an increase in $\tau$. In the offshoring case, since an increase in $\tau$ does not affect the decision of offshoring firms who do not use domestic unskilled labor, the rewards of skilled workers are pinned down by the offshoring cost, $p_{m}$, which is unchanged. Any change in the decision of non-offshoring firms affects the wage and unemployment of only the unskilled labor as long as both types of firms continue to exist.

A more detailed reasoning goes as follows. Because we are making a small country assumption, the home country takes the world price of the imported service or input (that replaces domestic unskilled workers) as given. Because of free entry that leads to zero profits in equilibrium (for both offshoring and completely domestic firms that exist in equilibrium), this fixed input price pins

\footnotetext{
${ }^{18}$ Technically speaking, the sufficient condition holds when the overhiring effect is relatively small in magnitude.
} 
down the tightness of the market for skilled labor (and therefore also the skilled wage, the hiring cost of a skilled worker and skilled unemployment). Given this fixed skilled wage and the fixed skilled-worker hiring cost, the free entry-condition (zero-profit condition) of the totally domestic firms pins down the sum of the wage and the hiring cost of an unskilled worker. ${ }^{19}$ As the fairness parameter (the preference for fairness) goes up, the unskilled wage goes up, given the constant skilled wage. However, in the face of this increase in unskilled wage, the sum of the unskilled wage and hiring cost per unskilled worker will remain constant, only if the recruitment cost of unskilled labor goes down. This will happen through a reduction in its market tightness resulting in an increase in unskilled unemployment.

\section{Extensions in the offshoring case}

\subsection{Relaxing the small country assumption}

We have so far assumed that the home country is small in the market for the imported input in that it faces a fixed international price of that input. This assumption is key in fully insulating the skilled labor market from the impact of a change in the fairness parameter in the offshoring case. If we relax the small country assumption and now assume that $p_{m}$ is increasing in the amount of offshoring, the home country then faces an upward sloping export supply of this input. Assuming that each firm is still a price taker in the input market, we can use the results of the previous comparative static exercise with respect to $p_{m}$ to derive a downward sloping import demand from the home country for the offshored input. An increase in the fairness parameter, $\tau$ results in a rightward shift in the import-demand curve and increases the equilibrium $p_{m}$. This, in turn, will reduce skilled wage and increase skilled unemployment. How much of this change takes place will depend on the elasticity of export supply faced by the home country. The results we showed earlier were for the special case of perfectly elastic export supply. The extent to which the market for skilled labor is insulated from the impact of changes in the fairness parameter is increasing in the elasticity of export supply. The reason is that the more elastic the export supply is the

\footnotetext{
${ }^{19}$ It is easy to check in the case of a fully domestic firm facing a binding fair-wage constraint using the first-order conditions combined with the differential equation arising out of wage bargaining that, at a given $\theta_{s}$, both $t$ and $\tau w_{s}+\frac{c_{l}}{q\left(\theta_{l}\right)}$ get fixed and are independent of $\tau$.
} 
greater the adjustment in the amount of offshoring that can happen in response to a change in the fairness parameter. As mentioned before, this adjustment in the amount of offshoring replaces the adjustment in the skilled labor market. Thus, as long as the export supply is not perfectly inelastic, we will still at least partially insulate the market for skilled labor from the impact of a change in the fairness parameter. However, in the imperfectly elastic case, the impact that we saw earlier on unskilled labor market outcomes will be somewhat muted.

\subsection{Offshoring in the presence of an endogenous preference for fairness}

Let us relax the assumption that $\tau$ is a scalar and assume that $\tau$ is a decreasing function of unskilled unemployment, which means it is an increasing function of the market tightness for unskilled workers. In other words, given a skilled wage, what unskilled wage is considered fair is lower, the higher is the unskilled unemployment rate. When there is a vast number of jobless unskilled individuals, unskilled workers will be willing to accept a lower wage as a fair wage. In Proposition 4 we derived the equilibrium $\theta_{l}$ as a decreasing function of $\tau$ in the offshoring case. This is represented in Figure 2 by the downward sloping curve, $\theta_{l}(\tau) .{ }^{20}$ The level of $\tau$ the society is willing to accept as a norm is given by the upward sloping curve, $\tau^{n}\left(\theta_{l}\right)$. The intersection of $\tau^{n}\left(\theta_{l}\right)$ with $\left[\theta_{l}(\tau)\right]_{1}$ gives us our initial equilibrium. We know from here the equilibrium $\theta_{l}$ and $\tau$. Note that our main model with a scalar $\tau$ is a special case of this analysis where $\tau^{n}\left(\theta_{l}\right)$ is vertical.

The main comparative static we study here is a reduction in the offshoring cost, $p_{m}$. Using Proposition 3 , for any given $\tau$, we will see a reduction in $\theta_{l}$ as a result of a reduction in the offshoring cost, $p_{m}$. Starting from our initial equilibrium given by the intersection of $\tau^{n}\left(\theta_{l}\right)$ with $\left[\theta_{l}(\tau)\right]_{1}$, we will now see a downward shift of the $\theta_{l}(\tau)$ curve from $\left[\theta_{l}(\tau)\right]_{1}$ to $\left[\theta_{l}(\tau)\right]_{2}$. This results in a reduction in the equilibrium $\theta_{l}$ and $\tau$. Thus, offshoring increases unskilled unemployment and at the same time reduces the society's preference for fairness. Since the preference for fairness is endogenous to unskilled unemployment and decreasing in it, the impact of the reduction in the offshoring cost on unskilled unemployment gets muted. Our basic result is that as a result of offshoring the society is willing to accept a higher wage inequality. This, in turn, results in a smaller increase in unskilled unemployment than if the maximum permissible wage inequality were fixed.

\footnotetext{
${ }^{20}$ The figure is drawn under the assumption that the fairness constraint is binding.
} 


\section{Concluding remarks}

In this paper, we have studied the effects of introducing a fair-wage constraint in a two-factor general-equilibrium model of unemployment with search frictions. While the effect of a fair-wage constraint on unskilled workers is in the form of an increase in their wage and unemployment, we also find interesting effects on skilled workers in a closed economy. The skilled wage and skilled unemployment move in directions opposite to each other, with the actual direction of their movement depending on the elasticity of substitution between skilled and unskilled labor.

Extending the model to look at the implications of offshoring in the presence of fairness considerations, we show that a decrease in the cost of offshoring increases the extent of offshoring, reduces skilled unemployment, increases both skilled and unskilled wage and increases unskilled unemployment. Since skilled and unskilled unemployment move in opposite directions, the impact on aggregate unemployment is ambiguous. Starting from an offshoring equilibrium where the fairness constraint is binding, an increase in the concern for fairness leaves the unemployment rate and wage of skilled workers remain unchanged. Thus the effects on skilled workers, due to a change in the preference for fairness under autarky, go away when we allow for offshoring of the services of unskilled labor. These effects get replaced by the impact on the amount of offshoring taking place.

\section{References}

[1] Akerlof, George A. and Robert J. Shiller (2009). Animal Spirits: How Human Psychology Drives the Economy and Why it Matters for Global Capitalism, Princeton University Press, Princeton and Oxford.

[2] Akerlof, George A and Yellen, Janet L (1990). "The Fair-Wage-Effort Hypothesis and Unemployment," The Quarterly Journal of Economics 105(2), 255-83.

[3] Alesina, Alberto and George-Marios Angeletos (2005). "Fairness and Redistribution," American Economic Review 95(4), 960-980.

[4] Alesina, Alberto and Edward Glaeser (2006). Fighting Poverty in the US and Europe: A World of Difference, Oxford University Press. 
[5] Bewley, Truman (2005). "Fairness, Reciprocity, and Wage Rigidity," In: Gintis, H., Bowles, S., Boyd, R., Fehr, E. (Eds.), Moral Sentiments and Material Interests: The Foundations of Cooperation in Economic Life, MIT Press, Cambridge, MA.

[6] Cahuc, Pierre; Marque, Francois and Wasmer, Etienne (2008). "A Theory Of Wages And Labor Demand With Intra-Firm Bargaining And Matching Frictions," International Economic Review 49(3), 943-972.

[7] Davidson, Carl and Steven Matusz (2004). International Trade and Labor Markets: Theory, Evidence, and Policy Implications, Upjohn Institute Press, Kalamazoo, Michigan.

[8] Davidson, Carl; Matusz, Steven and Douglas Nelson (2012). "A Behavioral Model of Unemployment, Sociotropic Concerns and the Political Economy of Trade Policy," Economics and Politics 24(1), 72-94.

[9] Egger, Harmut and Kreickemeier, Udo (2009). "Firm Heterogeneity and the Labor Market Effects of Trade Liberalization," International Economic Review 50, 187-216.

[10] Felbermayr, Gabriel; Larch, Mario and Lechthaler, Wolfgang (2008). "Unemployment in an Interdependent World," CESifo Working Paper 2788.

[11] Felbermayr, Gabriel; Prat, Julien and Schmerer, Hans-Jörg (2011) "Globalization and Labor Market Outcomes: Wage Bargaining, Search Frictions, and Firm Heterogeneity," Journal of Economic Theory, 146(1), 2011, 39-73.

[12] Grossman, Gene and Elhanan Helpman (2008). "Fair Wages and Foreign Sourcing," in E. Helpman, D.Marin, and T.Verdier eds., The Organization of Firms in a Global Economy, Harvard University Press.

[13] Helpman, E. and O. Itskhoki, (2010). "Labor market rigidities, trade and unemployment," Review of Economic Studies 77(3),1100-1137.

[14] Helpman, Elhanan and Itskhoki, Oleg. (2009): "Labor Market Rigidities, Trade and Unemployment: A Dynamic Model," Mimeo, Department of Economics, Harvard University.

[15] Helpman, Elhanan; Itskhoki, Oleg and Redding, Stephen (2010). "Inequality and Unemployment in a Global Economy," Econometrica 78(4), 1239-1283. 
[16] Howitt, Peter (2005). "Looking Inside the Labor Market: A Review Article," Journal of Economic Literature 40, pp. 125-138.

[17] Kreickemeier, Udo and Douglas Nelson (2006). "Fair Wages, Unemployment and Technological Change in a Global Economy," Journal of International Economics 70, 451-469.

[18] Mortensen, Dale and and Pissarides, Christopher (1999). "New Developments in Models of Search in the Labor Market, Ch. 39 in Ashenfelter and Card (eds), Handbook of Labor Economics, volume 3B, Elsevier.

[19] OECD (2007). OECD Employment Outlook, OECD.

[20] Osberg, Lars and Timothy Smeeding (2006). "Fair Inequality?' Attitudes Towards Pay Differentials: The United States in Comparative Perspective," American Sociological Review 71, 450-473.

[21] Pissarides, Christopher (2000). Equilibrium Unemployment Theory, 2nd Edition, MIT Press, Cambridge, MA.

[22] Stole, Lars A. and Jeffrey Zwiebel (1996), "Intra-Firm Bargaining under Non-Binding Contracts," Review of Economic Studies 63, pp. 375-410.

\section{Appendix A}

\subsection{Proof of lemma 3}

From (21) obtain $f^{\prime}\left(t^{d}\right)-\left(t^{d}+\tau\right) \frac{\partial w_{s}\left(t^{d}, \tau\right)}{\partial t^{d}}=\frac{w_{s}\left(t^{d}, \tau\right)}{\beta}$. Therefore, write the numerator of $\Psi\left(t^{d}, \tau\right)$ as $\frac{1-\beta}{\beta} w_{s}\left(t^{d}, \tau\right)$. Since $\frac{\partial w_{s}\left(t^{d}, \tau\right)}{\partial t^{d}}<0$, the numerator of $\Psi\left(t^{d}, \tau\right)$ is decreasing in $t^{d}$. Next, using (21) verify that $\left(f\left(t^{d}\right)-t^{d} f^{\prime}\left(t^{d}\right)+\left(t^{d 2}+\tau t^{d} t\right) \frac{\partial w_{s}\left(t^{d}, \tau\right)}{\partial t^{d}}\right)=f\left(t^{d}\right)-\frac{t^{d} w_{s}\left(t^{d}, \tau\right)}{\beta}$. Therefore, write the denominator of $\Psi\left(t^{d}, \tau\right)$ as $f\left(t^{d}\right)-\frac{t^{d} w_{s}\left(t^{d}, \tau\right)}{\beta}-\tau w_{s}\left(t^{d}, \tau\right)$. Next, verify that Hence,

$$
\begin{aligned}
\frac{\partial\left(f\left(t^{d}\right)-\frac{t^{d} w_{s}\left(t^{d}, \tau\right)}{\beta}-\tau w_{s}\left(t^{d}, \tau\right)\right)}{\partial t^{d}} & =f^{\prime}\left(t^{d}\right)-\frac{w_{s}\left(t^{d}, \tau\right)}{\beta}-\frac{t^{d}}{\beta} \frac{\partial w_{s}\left(t^{d}, \tau\right)}{\partial t^{d}}-\tau \frac{\partial w_{s}\left(t^{d}, \tau\right)}{\partial t^{d}} \\
& =\left(t^{d}+\tau\right) \frac{\partial w_{s}\left(t^{d}, \tau\right)}{\partial t^{d}}-\frac{t^{d}}{\beta} \frac{\partial w_{s}\left(t^{d}, \tau\right)}{\partial t^{d}}-\tau \frac{\partial w_{s}\left(t^{d}, \tau\right)}{\partial t^{d}} \\
& =-\frac{1-\beta}{\beta} t^{d} \frac{\partial w_{s}\left(t^{d}, \tau\right)}{\partial t^{d}}>0
\end{aligned}
$$


THe last inequality follows from $\frac{\partial w_{s}\left(t^{d}, \tau\right)}{\partial t^{d}}<0$. Therefore, we have established that $\frac{\partial \Psi\left(t^{d}, \tau\right)}{\partial}<0$. This in turn implies that $t^{d}$ is decreasing in $\frac{\theta_{s}}{\theta_{l}}$.

\subsection{Proof of Lemma 5}

The relative demands in the unconstrained and constrained cases can be obtained from (14) and (23), respectively, which we recall are

$$
\begin{aligned}
\frac{f^{\prime}\left(t^{d}\right)-w_{s}\left(t^{d}\right)}{f\left(t^{d}\right)-t^{d} f^{\prime}\left(t^{d}\right)-w_{l}\left(t^{d}\right)} & =\frac{c_{s}}{c_{l}}\left(\frac{\theta_{s}}{\theta_{l}}\right)^{1-\delta} \\
\frac{f^{\prime}\left(t^{d}\right)-w_{s}\left(t^{d}, \tau\right)-\left(t^{d}+\tau\right) \frac{\partial w_{s}\left(t^{d}, \tau\right)}{\partial t^{d}}}{f\left(t^{d}\right)-t^{d} f^{\prime}\left(t^{d}\right)+\left(\left(t^{d}\right)^{2}+\tau t^{d}\right) \frac{\partial w_{s}\left(t^{d}, \tau\right)}{\partial t^{d}}-\tau w_{s}\left(t^{d}, \tau\right)} & =\frac{c_{s}}{c_{l}}\left(\frac{\theta_{s}}{\theta_{l}}\right)^{1-\delta}
\end{aligned}
$$

Since $\left.\frac{\partial w_{s}\left(t^{d}, \tau\right)}{\partial t^{d}}\right)<0$ and $\tau w_{s}\left(t^{d}, \tau\right) \geq w_{l}\left(t^{d}\right)$ whenever the constraint is binding, the denominator of (40) is smaller than the denominator of (39) for any $t$. Recall from lemma 1 that $w_{s}\left(t^{d}\right)=\beta f^{\prime}\left(t^{d}\right)$ in the unconstrained case, therefore, the numerator of (39) is simply $(1-\beta) f^{\prime}\left(t^{d}\right)$. Next, using (21) the numerator of $(40)$ can be written as $(1-\beta)\left(f^{\prime}\left(t^{d}\right)-\left(t^{d}+\tau\right) \frac{\partial w_{s}\left(t^{d}, \tau\right)}{\partial t^{d}}\right)$ which is clearly greater than $(1-\beta) f^{\prime}\left(t^{d}\right)$ if $\frac{\partial w_{s}\left(t^{d}, \tau\right)}{\partial t^{d}}<0$. Q.E.D.

\subsection{Proof of lemma 6}

Suppose not. Suppose $\theta_{l}^{c} \geq \theta_{l}^{u}$. Since $\frac{\theta_{s}^{c}}{\theta_{l}^{c}}>\frac{\theta_{s}^{u}}{\theta_{l}^{u}}$, it implies $\theta_{s}^{c}>\theta_{s}^{u}$. Let the input combination per unit of output be $\left(a s^{u}, a l^{u}\right)$ and $\left(a s^{c}, a l^{c}\right)$ in the unconstrained and constrained equilibrium respectively. The zero profit condtion in the unconstrained case is given by $F(s, l)=$ $\left(w_{s}(s, l)+\frac{c_{s}}{q\left(\theta_{s}\right)}\right) s+\left(w_{l}(s, l)+\frac{c_{l}}{q\left(\theta_{l}\right)}\right) l$, which is satisfied when (5) and (6) are satisfied. Using lemma 2 and the zero profit condition we obtain $\frac{1}{1-\beta} \frac{c_{s}}{q\left(\theta_{s}^{u}\right)} a s^{u}+\frac{1}{1-\beta} \frac{c_{l}}{q\left(\theta_{l}^{u}\right)} a l^{u}=1$. When (19) and (20) are satisfied, the zero profit condition is satisfied in the constrained case as well, that is $F(s, l)=\left(w_{s}(s, l)+\frac{c_{s}}{q\left(\theta_{s}\right)}\right) s+\left(\tau w_{s}(s, l)+\frac{c_{l}}{q\left(\theta_{l}\right)}\right) l$. Therefore, using lemma 4 and the zero profit condition we get $\frac{1}{1-\beta} \frac{c_{s}}{q\left(\theta_{s}^{c}\right)} a s^{c}+\left[\frac{\tau \beta}{1-\beta} \frac{c_{s}}{q\left(\theta_{s}^{c}\right)}+\frac{c_{l}}{q\left(\theta_{l}^{c}\right)}\right] a l^{c}=1$. From the optimality conditions of the profit maximization problem of an unconstrained firm in equilibrium, it must be true that $\frac{1}{1-\beta} \frac{c_{s}}{q\left(\theta_{s}^{u}\right)} a s^{c}+\frac{1}{1-\beta} \frac{c_{l}}{q\left(\theta_{l}^{u}\right)} a l^{c}>1$ (that is, since at $\theta_{s}^{u}, \theta_{l}^{u}$ the optimal choice $\left(a s^{u}, a l^{u}\right.$ ) leads to profit maximization, the choice of $\left(a s^{c}, a l^{c}\right)$ should lead to losses). Now since $\theta_{l}^{c} \geq \theta_{l}^{u}$ and $\theta_{s}^{c}>\theta_{s}^{u}$, and since a binding (or a just binding) fair-wage constraint (at the constrained equilibrium) implies 
$\tau \geq \frac{c_{l} q\left(\theta_{s}^{c}\right)}{c_{s} q\left(\theta_{l}^{c}\right)}$, we have $\frac{1}{1-\beta} \frac{c_{s}}{q\left(\theta_{s}^{c}\right)} a s^{c}+\left[\frac{\tau \beta}{1-\beta} \frac{c_{s}}{q\left(\theta_{s}^{c}\right)}+\frac{c_{l}}{q\left(\theta_{l}^{c}\right)}\right] a l^{c}>\frac{1}{1-\beta} \frac{c_{s}}{q\left(\theta_{s}^{u}\right)} a s^{c}+\frac{1}{1-\beta} \frac{c_{l}}{q\left(\theta_{l}^{u}\right)} a l^{c}>1$. That is, $\frac{1}{1-\beta} \frac{c_{s}}{q\left(\theta_{s}^{c}\right)} a s^{c}+\left[\frac{\tau \beta}{1-\beta} \frac{c_{s}}{q\left(\theta_{s}^{c}\right)}+\frac{c_{l}}{q\left(\theta_{l}^{c}\right)}\right] a l^{c}>1$, which is a contradiction. Therefore, $\theta_{l}^{c}<\theta_{l}^{u}$. Q.E.D.

\subsection{Proof of lemma 7}

From the proof of lemma 3 above note that using using $(21), \Psi\left(t^{d}, \tau\right)$ can be written as

$$
\Psi\left(t^{d}, \tau\right) \equiv \frac{\left(\frac{1-\beta}{\beta}\right) w_{s}\left(t^{d}, \tau\right)}{f\left(t^{d}\right)-\frac{1}{\beta} t^{d} w_{s}\left(t^{d}, \tau\right)-\tau w_{s}\left(t^{d}, \tau\right)}
$$

Taking the derivative of the above with respect to $\tau$ and after cancelling terms obtain

$$
\frac{\partial \Psi\left(t^{d}, \tau\right)}{\partial \tau}=\left(\frac{1-\beta}{\beta}\right) \frac{f\left(t^{d}\right) \frac{\partial w_{s}\left(t^{d}, \tau\right)}{\partial \tau}+\left(w_{s}\left(t^{d}, \tau\right)\right)^{2}}{\left(f\left(t^{d}\right)-\frac{1}{\beta} t w_{s}\left(t^{d}, \tau\right)-\tau w_{s}\left(t^{d}, \tau\right)\right)^{2}}
$$

Therefore, a sufficient condition for $\frac{\partial \Psi\left(t^{d}, \tau\right)}{\partial \tau}>0$ is $\frac{\partial w_{s}\left(t^{d}, \tau\right)}{\partial \tau} \geq 0$.

\subsection{Proof of lemma 9}

First verify that the l.h.s of (27) is increasing in $t^{o}$. Therefore, a decrease in $p_{m}$ implies a decrease in $t^{o}$. Since offshored input has become cheaper, offshoring firms increase their offshoring intensity and economize on skilled labor. Since $w_{s}^{o \prime}\left(t^{o}\right)<0$, it implies an increase in skilled wage, and hence an increase in $\theta_{s}$ from lemma 8 . Lemma 8 also implies a decrease in $t^{n o}$ since $\frac{\partial w_{s}^{n o}\left(t^{n o}, \tau\right)}{\partial t^{n o}}<0$ (from assumption 2) and $w_{s}^{n o}\left(t^{n o}, \tau\right)$ has increased. The impact on unskilled unemployment depends on what happens to the l.h.s of (31). Denoting the l.h.s of (31) by $\Phi$, and upon using (32), write $\Phi$ as

$$
\Phi=f\left(t^{n o}\right)-\left(\frac{t^{n o}}{\beta}+\tau\right) w_{s}^{n o}\left(t^{n o}, \tau\right)
$$

Therefore,

$$
\frac{d \Phi}{d p_{m}}=-\frac{1-\beta}{\beta} t^{n o} \frac{\partial w_{s}^{n o}\left(t^{n o}, \tau\right)}{\partial t^{n o}} \frac{d t^{n o}}{d p_{m}}>0
$$

The above inequality follows from the result that $\frac{d t^{n o}}{d p_{m}}>0$ and $\frac{\partial w_{s}^{n o}\left(t^{n o}, \tau\right)}{\partial t^{n o}}<0$. Therefore, $\frac{d \theta_{l}}{d p_{m}}>0$.

Finally, $\frac{d \theta_{s}}{d p_{m}}<0$ and $\frac{d \theta_{l}}{d p_{m}}>0$ imply an increase in $s^{o}+s^{n o}$ and a decrease in $l$ when $p_{m}$ decreases. Since $\frac{d t^{n o}}{d p_{m}}>0$, a decrease in $l$ implies a decrease in $s^{n o}$, which in turn implies an increase in $s^{o}$. Since $t^{o}$ has decreased, $m$ must increase. 


\subsection{Proof of Lemma 10}

Taking the total derivative of (43) with respect to $\tau$ and using the result that $\frac{d w_{s}^{n o}\left(t^{n o}\right)}{d \tau}=0$ obtain

$$
\frac{d \Phi}{d \tau}=\left(f^{\prime}\left(t^{n o}\right)-\frac{w_{s}^{n o}\left(t^{n o}, \tau\right)}{\beta}\right) \frac{d t^{n o}}{d \tau}-w_{s}^{n o}\left(t^{n o}, \tau\right)<0
$$

The above inequality follows from the fact that $w_{s}^{n o}\left(t^{n o}, \tau\right)>\beta f^{\prime}\left(t^{n o}\right)$ and it was shown earlier that $\frac{d t^{n o}}{d \tau} \geq 0$.

\subsection{Impact of offshoring in the unconstrained case}

The offshoring firms solve the following problem.

$$
\underset{s, m}{\operatorname{Max}} F(s, m)-w_{s}(s, m) s-p_{m} m-\frac{c_{s}}{q\left(\theta_{s}\right)} s
$$

The first order conditions for the above maximization are given by

$$
\begin{aligned}
f^{\prime}\left(t^{o}\right)-w_{s}^{o}\left(t^{o}\right)-t^{o} w_{s}^{o \prime}\left(t^{o}\right) & =\frac{c_{s}}{q\left(\theta_{s}\right)} \\
f\left(t^{o}\right)-t^{o} f^{\prime}\left(t^{o}\right)+t^{o 2} w_{s}^{o \prime}\left(t^{o}\right) & =p_{m}
\end{aligned}
$$

In the above expressions, the superscript $o$ denotes offshoring firms and $t^{o}$ equals $s^{o} / m$. Following the same procedure as in autarky, the wage of skilled workers in the second stage is given by the following differential equation

$$
w_{s}^{o}\left(t^{o}\right)=\beta\left[f^{\prime}\left(t^{o}\right)-t^{o} w_{s}^{o \prime}\left(t^{o}\right)\right]
$$

The solution to the above differential equation is given by

$$
w_{s}^{o}\left(t^{o}\right)=t^{o-\frac{1}{\beta}} \int_{0}^{t^{o}} x^{\frac{1-\beta}{\beta}} f^{\prime}(x) d x
$$

For a non-offshoring firm, the first order conditions are the same as in autarky given in (19) and (20) which we recall are

$$
\begin{aligned}
f^{\prime}\left(t^{n o}\right)-w_{s}^{n o}\left(t^{n o}\right)-t^{n o} w_{s}^{n o l}\left(t^{n o}\right)-w_{l}\left(t^{n o}\right) & =\frac{c_{s}}{q\left(\theta_{s}\right)} \\
f\left(t^{n o}\right)-t^{n o} f^{\prime}\left(t^{n o}\right)-w_{l}\left(t^{n o}\right)+t^{n o 2} w_{s}^{n o l}\left(t^{n o}\right)+t^{n o} w_{l}\left(t^{n o}\right) & =\frac{c_{l}}{q\left(\theta_{l}\right)}
\end{aligned}
$$

Nash bargaining implies the following wages for the two types of workers. 


$$
\begin{aligned}
w_{s}^{n o}\left(t^{n o}\right) & =\beta f^{\prime}\left(t^{n o}\right) \\
w_{l} & =\beta\left(f\left(t^{n o}\right)-t^{n o} f^{\prime}\left(t^{n o}\right)\right)
\end{aligned}
$$

The aggregate constraints can be written as follows.

$$
t^{o}=\frac{s^{o}}{m} ; t^{n o}=\frac{s^{n o}}{l} ; s^{o}+s^{n o}=S k \theta_{s}^{\delta} ; l=L k \theta_{l}^{\delta}
$$

Therefore, the above 11 equations ((45), (46), (48), (49), (50), (51), (52) and (53)) determine the key endogenous variables: $t^{n o}, t^{o}, w_{s}^{n o}, w_{s}^{o}, w_{l}, \theta_{s}, \theta_{l}, s^{o}, s^{n o}, m, l$.

Even though $t^{o} \neq t^{n o}$, the following lemma again holds

$$
\text { Lemma 8': } w_{s}^{n o}=w_{s}^{o}=\frac{\beta}{1-\beta} \frac{c_{s}}{q\left(\theta_{s}\right)}
$$

Since both types of firms use skilled workers and face the same recruitment cost, they end up paying the same skilled wage.

Now, look at the impact of a decrease in $p_{m}$.

First verify that the l.h.s of (46) is increasing in $t$. Therefore, a decrease in $p_{m}$ implies a decrease in $t^{o}$. Since $w_{s}^{\prime}\left(t^{o}\right)<0$, it implies an increase in skilled wage, and hence an increase in $\theta_{s}$ from lemma

8'. Lemma 8' also implies a decrease in $t^{n o}$ since $\frac{\partial w_{s}^{n o}(t)}{\partial t}<0$ and $w_{s}^{n o}\left(t^{n o}\right)$ has increased. This confirms the result for skilled labor. The impact on unskilled labor is the following. A decrease in $t^{n o}$ implies a decrease in unskilled wage from (52). Note from (50) and (52) that $w_{l}\left(t^{n o}\right)=\frac{\beta}{1-\beta} \frac{c_{l}}{q\left(\theta_{l}\right)}$, and therefore, a decrease in $w_{l}$ implies a decrease in $\theta_{l}$ and consequently an increase in unskilled unemployment. Q.E.D.

\subsection{Fair Wage Determined at the Industry level}

Now, the entrepreneur's problem effectively becomes:

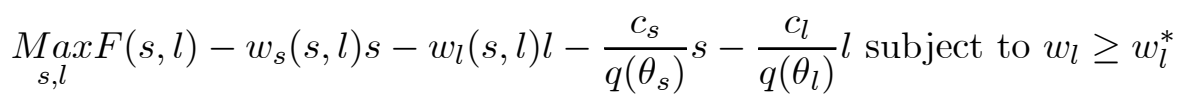

Assuming that $w_{l}^{*}$, determined at the industry level, is taken by the firm parametrically (as given), for a firm anticipating a binding fair-wage constraint in the second stage, the first-order conditions for the employment choice in the first stage become 


$$
\begin{aligned}
f^{\prime}(t)-w_{s}-s \frac{\partial w_{s}}{\partial s} & =\frac{c_{s}}{q\left(\theta_{s}\right)} \\
f(t)-t f^{\prime}(t)-w_{l}^{*}-s \frac{\partial w_{s}}{\partial l} & =\frac{c_{l}}{q\left(\theta_{l}\right)}
\end{aligned}
$$

Write $w_{s}$ as a function of $t=s / l$. Using Nash bargaining the wage of a skilled worker is given by the following differential equation

$$
w_{s}(t)=\beta\left[f^{\prime}(t)-t w_{s}^{\prime}(t)\right]
$$

The solution to the above differential equation is given by

$$
w_{s}(t)=t^{-\frac{1}{\beta}} \int_{0}^{t} x^{\frac{1-\beta}{\beta}} f^{\prime}(x) d x
$$

Under the assumption that $w_{l}^{*}=\tau w_{s}$, the analogue of (??) in the text is given by

$$
\frac{f^{\prime}(t)-w_{s}(t)-t w_{s}^{\prime}(t)}{f(t)-t f^{\prime}(t)+t^{2} w_{s}^{\prime}(t)-\tau w_{s}(t)}=\frac{c_{s}}{c_{l}}\left(\frac{\theta_{s}}{\theta_{l}}\right)^{1-\delta}
$$

Next, verify that $w_{s}^{\prime}(t)<0$. From equation (58) obtain

$$
w_{s}^{\prime}(t)=-\frac{1}{\beta} t^{-\frac{1}{\beta}-1} \int_{0}^{t} x^{\frac{1-\beta}{\beta}} f^{\prime}(x) d x+\frac{f^{\prime}(t)}{t}
$$

Using integration by parts and after canceling terms out obtain

$$
w_{s}^{\prime}(t)=t^{-\frac{1}{\beta}-1}\left(\int_{0}^{t} x^{\frac{1}{\beta}} f^{\prime \prime}(x) d x\right)<0 \text { since } f^{\prime \prime}(x)<0
$$

Next,

$$
\frac{d\left(f(t)-t f^{\prime}(t)+t^{2} w_{s}^{\prime}(t)\right)}{d t}=-t f^{\prime \prime}(t)+2 t w_{s}^{\prime}(t)+t^{2} w_{s}^{\prime \prime}(t)
$$

From (57) obtain

$$
t w_{s}^{\prime \prime}(t)=\left[f^{\prime \prime}(t)-w_{s}^{\prime}(t)-\frac{w_{s}^{\prime}(t)}{\beta}\right]
$$

Use (63) in (62) to obtain

$$
\frac{d\left(f(t)-t f^{\prime}(t)+t^{2} w_{s}^{\prime}(t)\right)}{d t}=-\frac{(1-\beta) t w_{s}^{\prime}(t)}{\beta}>0
$$

The analogue of lemma 3 is as follows. 
Lemma 3': The relative demand given in (59) is decreasing in $\frac{\theta_{s}}{\theta_{l}}$.

Proof: $w_{s}^{\prime}(t)<0$ and $\frac{d\left(f(t)-t f^{\prime}(t)+t^{2} w_{s}^{\prime}(t)\right)}{d t}>0$ imply that the numerator of the 1.h.s of (59) is decreasing in $t$, and the denominator is increasing in $t$. Hence, the relative demand for skilled labor is decreasing in $\frac{\theta_{s}}{\theta_{l}}$.

Therefore, we get a constrained equilibrium similar to that in the text for the firm fair wage case. It is easy to verify that lemmas 4,5 , and 6 easily hold in the industry fair wage case as well, and hence, proposition 1 holds in this case as well.

\subsubsection{Comparative statics with respect to $\tau$}

Starting with an equilibrium where the fair wage constraint binds, it can be easily verified that an increase in $\tau$ implies a rightward shift in the expression on the left in (59). This implies an increase in the equilibrium $t$ and $\frac{\theta_{s}}{\theta_{l}}$. From lemmas 3 and 4 it implies a decrease in $w_{s}$ and $\theta_{s}$. Since $\frac{\theta_{s}}{\theta_{l}}$ has increased while $\theta_{s}$ has decreased, $\theta_{l}$ must decrease even more. Finally, lemma 3' part $\mathrm{b}$ and the f.o.c for unskilled labor written as $f(t)-t f^{\prime}(t)+t^{2} w_{s}^{\prime}(t)-\tau w_{s}(t)=\frac{c_{l}}{q\left(\theta_{l}\right)}$ imply that $\tau w_{s}(t)$, and hence the unskilled wage increases. This gives us the result summarized after proposition 2 in the paper. 


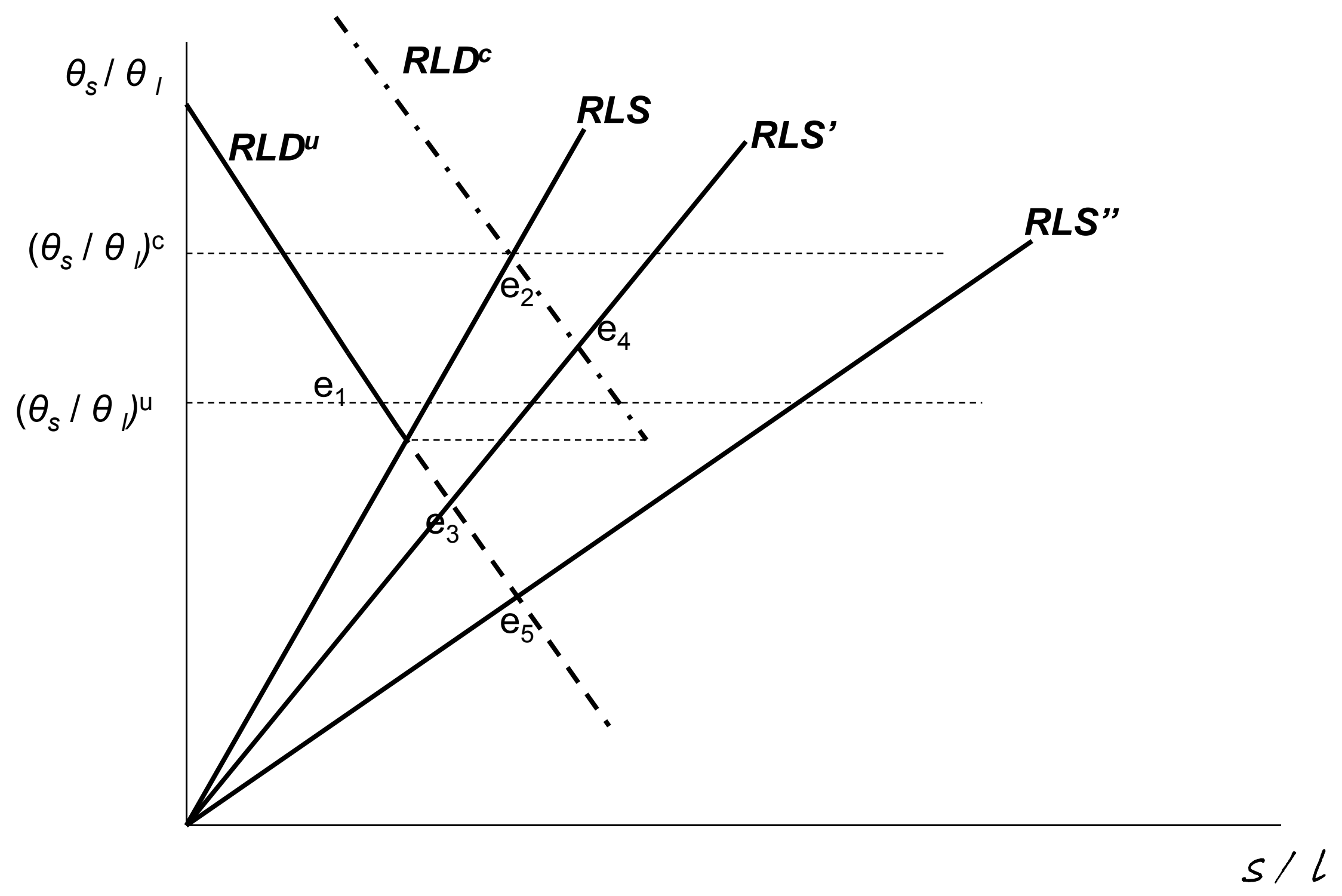

Figure 1: Determination of equilibrium 


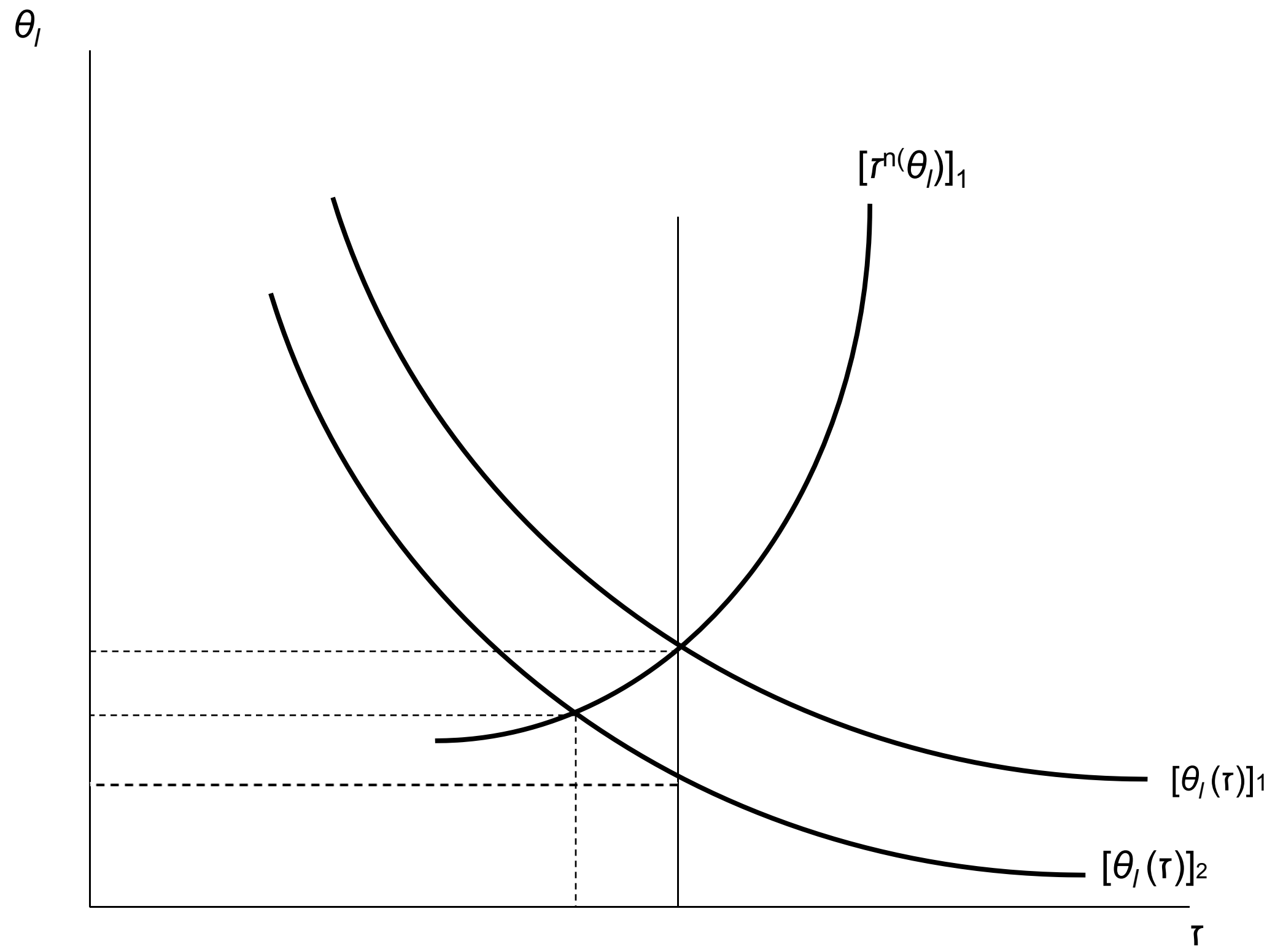

Figure 2: Equilibrium With Endogenous T 